\title{
LIKE ATTRACT LIKE? A STRUCTURAL COMPARISON OF HOMOGAMY ACROSS SAME-SEX AND DIFFERENT-SEX HOUSEHOLDS
}

\author{
EDOARDO CISCATO ${ }^{b}$, ALFRED GALICHON $^{\dagger}$, AND MARION GOUSSÉ $^{\S}$
}

\begin{abstract}
In this paper, we extend Gary Becker's empirical analysis of the marriage market to same-sex couples. Becker's theory rationalizes the well-known phenomenon of homogamy among different-sex couples: individuals mate with their likes because many characteristics, such as education, consumption behaviour, desire to nurture children, religion, etc., exhibit strong complementarities in the household production function. However, because of asymmetries in the distributions of male and female characteristics, men and women may need to marry "up" or "down" according to the relative shortage of their characteristics among the populations of men and women. Yet, among same-sex couples, this limitation does not exist as partners are drawn from the same population, and thus the theory of assortative mating would boldly predict that individuals will choose a partner with nearly identical characteristics. Empirical evidence suggests a very different picture: a robust stylized fact is that the correlation of the characteristics is in fact weaker among same-sex couples. In this paper, we build an equilibrium model of same-sex marriage market which allows for straightforward identification of the gains to marriage. We estimate the model with 2008-2012 ACS data on California and show that positive assortative mating is weaker for homosexuals than for heterosexuals with respect to age and race. Our results suggest that positive assortative mating with respect to education is stronger among lesbians, and not significantly different when comparing gay men and married different-sex couples. As regards labor market outcomes, such as hourly wages and working hours, we find some indications that the process of specialization within the household mainly applies to different-sex couples.
\end{abstract}

Keywords: sorting, matching, marriage market, homogamy, same-sex households, roommate problem.

JEL Classification: D1, C51, J12, J15.

Date: First circulated version: November 21, 2014. This version: August 2018. Galichon's research has been supported by NSF grant \# DMS-1716489, as well as ERC grants FP7-295298, FP7-312503, FP7-337665. The authors would like to thank the editor, James Heckman, and four anonymous referees as well as Arnaud Dupuy, Sonia Oreffice, Bernard Salanié and Simon Weber for useful discussion. Accepted for publication by the Journal of Political Economy Volume 128, Number 2, February 2020, URL: https://doi.org/10.1086/704611. 


\section{INTRODUCTION}

How individuals sort themselves into marriage has important implications for income distribution, labor supply, and inequality (Becker, 1973). Strong evidence shows that assortative mating in marriages accounts for a non-negligible part of income inequality across households (Eika et al., 2014).

Individuals tend to mate with their likes, a pattern called homogamy. However, because of asymmetries between the distributions of the characteristics in male and female populations, homogamy cannot be perfect among different-sex couples. In other words, heterosexuals cannot always find a "clone" of the opposite sex to match with. A large body of the literature has noticed that, up until recently, "men married down, women married up" due to the sex asymmetry in educational achievement that has only recently started to fade (Goldin et al., 2006). Gender asymmetries exist in other dimensions such as biological characteristics (windows of fertility ${ }^{1}$, life expectancy, bio-metric characteristics), psychological traits, economic attributes (due to the gender wage gap), ethnic and racial characteristics (immigration is not symmetric across sexes, see Weiss et al., 2013) or demographic characteristics (some countries, such as China, have comparatively more imbalanced gender ratios).

Homogamy has been famously studied by Becker's seminal analysis of the family. Becker, 1973 expects most non-labor market traits, such as "intelligence, height, skin color, age, education, family background or religion", to be complements. However, he also suggests that some attributes could be substitutes; in particular, Becker suggests that we should observe a negative correlation between some labor market traits such as wage rates because of household specialization ${ }^{2}$. In order to provide a structural explanation of homogamy, Becker proposed a model of positive assortative mating (PAM) in which men and women are characterized by some socio-economic "ability" index.

\footnotetext{
${ }^{1}$ Women's fertility rapidly declines with age, whereas men's fertility does not. Biologists and anthropologists argue that this dissymmetry could explain the well-documented preference of men for younger women (Hayes, 1995; Kenrick \& Keefe, 1992). Low, 2013 evaluates this young age premium for women and names it "reproductive capital," as it gives them an advantage on the marriage market over older women.

${ }^{2}$ P.-A. Chiappori et al., 2012 model a Becker-like marriage market with sorting on a unidimensional index. The estimation of such index reveals that high values in some attributes can compensate for poor values in others, thus showing that sorting is based on trade-offs between traits.
} 
In this model, the marriage market clears so that men are matched with women that are as close as possible to them in terms of this index, which subsumes all the characteristics that matter on the marriage market. The (strong) prediction of Becker's model is that the rank of the husband's index in the men's population is the same as the wife's in the women's population. However, this does not imply that the partners' indices are identical: they would be so only if the distributions of the indices were the same for both men and women's populations.

This analysis of the marriage market has attracted wide attention in the economic literature, in spite of its shortcomings. One shortcoming is that it originally refers to different-sex unions only. However, in a growing number of countries, same-sex couples have gained legal recognition, and the institutions of civil partnership and marriage no longer require that the partners must be of opposite sex. This official recognition is the result of several legal disputes and social activism by the gay and lesbian communities ${ }^{3}$. The issue of whether to recognize same-sex unions has long been a topical subject in many countries, since it challenges the traditional model of the family. From both an economic and a legal point of view, the definition of what "family" means has relevant political implications as long as this term is present - and is generally central - in many modern constitutions and legal systems. Consequently, family units benefit from a special attention of policy-makers. Therefore, a discussion of the issues related to same-sex marriage - remarkably at policy level - requires a good understanding of the similarities and differences in the household dynamics among same-sex and different-sex couples. Besides, it is important to remember that the legal recognition of same-sex couples is only one of many transformations that the institution of the family has gone through in the last decades (Stevenson, 2008; Stevenson \& Wolfers, 2007). Finally, since more and more data on same-sex unions have been made available, the extension of the economic analysis of family to the gay and lesbian population can now be taken to data.

While it is natural to consider an extension of Becker's model to same-sex households, it is worth noting that the previous considerations on asymmetries between men's and women's distributions only hold as long as each partner comes from a separate set according to his/her sex. On the samesex marriage market, the two partners are drawn from the same population and the distributions of

\footnotetext{
${ }^{3}$ Public actions for gay rights acknowledgment are often considered to have started in 1969, in New York City. See Eskridge Jr, 1993 and Sullivan, 2009 for a detailed history and a full overview of the arguments in favor of and against same-sex marriage.
} 
the characteristics are the same. Hence, the assortative mating theory pushed to its limits implies that, in this setting, partners should be exactly identical, i.e., each individual will choose to marry someone with identical characteristics.

In spite of such theoretical predictions, facts suggest a very different picture. Recent empirical results on the 1990 and 2000 American Census show that same-sex couples have less correlated attributes than different-sex ones, at least in terms of a variety of non-labor traits, including racial and ethnic background, age and education (L. K. Jepsen \& Jepsen, 2002; Schwartz \& Graf, 2009). Studies on Norway, Sweden (Andersson et al., 2006) and Netherlands (Verbakel \& Kalmijn, 2014) led to similar findings. In order to explain these systematic differences, the literature has suggested several possible reasons. A first consideration is that gay people might be forced to pick from a restricted pool because of their smaller numbers in the population, thus having a narrower choice when selecting their partner, resulting in a more diverse range of potential matches (Andersson et al., 2006; Harry, 1984; Kurdek \& Schmitt, 1987; Schwartz \& Graf, 2009; Verbakel \& Kalmijn, 2014). Furthermore, gay men and lesbians have been found to be more likely to live in urban neighborhoods than heterosexuals, and since diversities in socio-economic traits are stronger in cities, this facilitates the crossing of racial and social boundaries (D. Black et al., 2002; D. A. Black et al., 2007; Rosenfeld \& Kim, 2005). In light of these observations, one could argue that the same-sex marriage market is faced with stronger search frictions. Nevertheless, this might not necessarily be the case if the potential partners gather in specific locations, as it happens in cities and neighborhoods that are considered "gay-friendly" (D. A. Black et al., 2007). Other analysts argue that gay people may have different preferences than heterosexuals, as they tend to be less conservative than straight individuals. Some explanations in this regard point out that, since homosexuality is still considered in some cultures as at odds with prevailing social norms, gay men and lesbians might grow less inclined to passively accept social conventions, and consequently they would end up choosing their partner with fewer concerns about his/her background traits ${ }^{4}$

\footnotetext{
${ }^{4}$ Note that household location choice and social norms are strictly related: it has been reported that gay people often leave their town of origin and escape social pressure exerted by relatives and acquaintances and go living in larger cities reputed to be gay/lesbian-friendly (Rosenfeld \& Kim, 2005). Analogously, they are aware that they have more probabilities of avoiding discrimination by achieving higher educational levels and orienting their professional choices toward congenial working environments (Blumstein, Schwartz, et al., 1983; Verbakel \& Kalmijn, 2014).
} 
(Blumstein, Schwartz, et al., 1983; Meier et al., 2009; Schwartz \& Graf, 2009). The detachment from the community of origin and the research for more tolerant surroundings have an influence both on values and social norms and on the heterogeneity of interpersonal ties.

A part of these explanations has to do with individual preferences, whereas another part has to do with demographics, i.e., the distribution of the characteristics in the population. It is clear that the explanations listed in the former paragraph, while different in nature, are not mutually exclusive, but all contribute to a better understanding of the equilibrium patterns. For instance, a high correlation in education may arise from individual tastes (as individuals could find more desirable to match with a partner of similar educational background), but also from demographics (indeed, if some educational category represents a large share of individuals, this will increase odds of unions within this category, thus mechanically increasing the correlation in education). When comparing the heterosexual and homosexual population, this is particularly relevant as their compositions present significant differences (e.g., gay people are, on average, more educated than heterosexuals; see D. A. Black et al., 2007).

In this paper, we focus on differences in marital gains: we would like to compare the structure of complementarity and substitutability across same-sex and different-sex households. In order to do so, we need a methodology that helps us interpret the observation of matching patterns and disentangle the role played by household interactions from external demographic factors. This is achieved through a structural approach, which allows us to estimate the parameters of the marital surplus function in order to fit the patterns actually observed. Hence, this approach will require an equilibrium model of matching.

In the wake of Becker, 1973, 1991, the economic literature has modeled the marriage market as a bipartite matching game with transferable utility. A couple consists of two partners coming each from a separate or identical subpopulation (respectively, in the case of different-sex and same-sex unions). Both partners are characterized by vectors of attributes, such as education, wealth, age, physical attractiveness, etc. It is assumed that, when two partners with respective attributes $x$ and $y$ form a pair, they generate a surplus equal to $\Phi(x, y)$, which is shared endogenously between them. In the case of separate subpopulations (different-sex marriage), the landmark contribution of Choo and Siow, 2006 showed that the surplus function $\Phi$ can easily be estimated based on 
matching patterns modulo a distributional assumption on unobservable variations in preferences, and was followed by a rich literature (P.-A. Chiappori et al., 2017; Fox, 2010; Galichon \& Salanié, 2014, to cite a few). Dupuy and Galichon, 2014 extended Choo and Siow's model to the case of continuous attributes and propose the convenient bilinear parameterization $\Phi(x, y)=x^{\prime} A y$, where $A$ is a matrix called "affinity matrix" whose terms reflect the strength of assortativeness between two partners' attributes. However, the bipartite assumption is restrictive and does not allow to estimate the surplus on same-sex marriage markets, and, to the best of our knowledge, no such estimation procedure is proposed in the literature. In a theoretical paper, P. A. Chiappori et al., forthcoming focus on stable matchings in a finite population and show that, when the population to be matched is doubled by cloning, the same-sex marriage problem, or "unipartite matching problem" can be mathematically reformulated as a heterosexual matching problem, or "bipartite matching problem" ${ }^{5}$. In section 2 of the present paper, we apply an analogous reasoning to the empirically tractable, large-population, two-sided matching model of Dupuy and Galichon, 2014, in order to adapt their empirical strategy to the same-sex marriage market.

A few papers already deal with the issue of assortativeness among same-sex households, although none of them allows to draw conclusions on the structural parameters of the surplus function that drives the assortativeness. The most relevant benchmarks for the empirical results of this work are the aforementioned L. K. Jepsen and Jepsen, 2002 and Schwartz and Graf, 2009. Both papers make use of the American census data (1990 and 1990/2000 respectively) and find that members of different-sex couples are more alike than those of same-sex ones with respect to non-labor market traits. The heterogeneity in assortativeness is measured in a logit framework containing dedicated parameters for homogamy. In general, in a logit framework individuals choose their best option among all possibilities. However, this fails to take into account the fact that matching takes place under scarcity constraint on the various characteristics. In the present paper, we estimate a model of matching in which agents compete for a partner; our measures of assortativeness are given by the parameters of the surplus function in each market (gay, lesbian and heterosexual).

\footnotetext{
${ }^{5}$ In another recent theoretical work, Peski, 2017 extends the NTU framework of Dagsvik, 2000 and Menzel, 2015 and discusses the existence of stable matching in the unipartite case. Fox, 2018 proposes an empirically tractable TU framework that generalizes both the bipartite and the unipartite case, and applies it to the car parts industry.
} 
The contributions of the present paper are twofold. On a methodological level, this paper is the first to propose a structural estimator of the matching surplus which applies to same-sex households, or, more generally, to instances of the unipartite matching problem. On an empirical level, we provide evidence by means of a structural analysis that, as concerns age and ethnicity, different-sex couples exhibit a higher degree of assortativeness than same-sex ones. While we find, in line with previous results, that sorting on education is stronger among lesbians with respect to different-sex couples, our results suggest that assortativeness on education is not significantly different when comparing gay male and married different-sex couples. Further, we also look at labor market traits such as hourly wages and working hours. Comparing assortativeness on labor market outcomes between same-sex and different-sex couples hints to different family dynamics and differences in the household specialization process. Finally, we briefly discuss the estimates of the mutually exclusive affinity indices obtained through our saliency analysis.

The rest of the paper is organized as follows. Section 2 will present the model and section 3 the estimation procedure. We describe our data in section 4 and our results in section 5 . Section 6 concludes.

\section{THE MODEL}

In what follows, it is assumed that the full type of each individual, i.e., the complete set of all individual characteristics that matter for the marriage market (physical attributes, psychological traits, socio-economic variables, sex, sexual orientation, etc.), is fully observed by market participants. Each individual is characterized by a vector of observable characteristics $x \in \mathcal{X}=\mathbb{R}^{K}$, which constitutes his or her observable type. However, following Choo and Siow, 2006, we allow for a certain degree of unobserved heterogeneity by assuming that agents experience variations in tastes that are not observable to the analyst, but are observable to the agents. In this paper, types are assumed to be continuous, as in Dupuy and Galichon, 2014, hereafter DG, and Menzel, 2015. Assume that the distribution of the characteristics $x$ has a density function $f$ with respect to the Lebesgue measure. Without loss of generality, the marginal distribution of the attributes is assumed to be centered, i.e. $\mathbb{E}[X]=0$. 
2.1. Populations. A pair is an ordered set of individuals, denoted $\left[x_{1}, x_{2}\right]$ where $x_{1}, x_{2} \in \mathcal{X}$, in which the order of the partner matters, which implies that the pair $\left[x_{1}, x_{2}\right]$ will be distinguished from its inverse twin $\left[x_{2}, x_{1}\right]$. In empirical datasets, $x_{1}$ will often be denominated "head of the household" and $x_{2}$ "spouse of the head of the household" even though this denomination is used mainly for practical reasons and cannot be fully representative of the actual roles in the household ${ }^{6}$. A couple is an unordered set of individuals $\left(x_{1}, x_{2}\right)$, so that the couple $\left(x_{1}, x_{2}\right)$ coincides with the couple $\left(x_{2}, x_{1}\right)$. A matching is the density of probability $\pi\left(x_{1}, x_{2}\right)$ of drawing a couple $\left(x_{1}, x_{2}\right)$. Pairs $\left[x_{1}, x_{2}\right]$ and $\left[x_{2}, x_{1}\right]$ stand for the same couple, so that the density $\pi\left(x_{1}, x_{2}\right)$ is the sum of the density of $\left[x_{1}, x_{2}\right]$ and of the density of $\left[x_{2}, x_{1}\right]$, hence the symmetry condition $\pi\left(x_{1}, x_{2}\right)=\pi\left(x_{2}, x_{1}\right)$ holds. This symmetry constraint means that the position of the individual must not matter and thus that there are no predetermined "roles" within the couple that would be relevant for the analysis ${ }^{7}$.

We shall impose assumptions that will ensure that everyone is matched at equilibrium, hence the density of probability of type $x \in \mathcal{X}$ in the population is given by $\int_{\mathcal{X}} \pi\left(x, x^{\prime}\right) d x^{\prime}$, which counts the number of individuals of type $x$ matched either as the head of household in a couple $\left[x, x^{\prime}\right]$, or as the spouse of the head in a couple $\left[x^{\prime}, x\right]$. Thus, we are led to assume:

Assumption 1 (Populations). The density $\pi\left(x, x^{\prime}\right)$ over couples satisfies $\pi \in \mathcal{M}^{\text {sym }}(f)$, where

$$
\mathcal{M}^{\text {sym }}(f)=\left\{\pi \geq 0:\left(\begin{array}{c}
\int_{\mathcal{X}} \pi\left(x, x^{\prime}\right) d x^{\prime}=f(x) \forall x \in \mathcal{X} \\
\pi\left(x_{1}, x_{2}\right)=\pi\left(x_{2}, x_{1}\right) \forall x_{1}, x_{2} \in \mathcal{X}
\end{array}\right)\right\} .
$$

In contrast, in the classical bipartite problem, we try to match optimally two distinct populations (men and women) which are characterized by the same space of observable variables $\mathcal{X}$, and it is assumed that the distribution of the characteristics among the population of men has density $f$,

\footnotetext{
${ }^{6}$ We will come back in section 5.3 to this assumption that the roles of partners are exchangeable, which we test using a number of proxies for asymmetric household roles.

${ }^{7}$ Candelon and Dupuy, 2015 extend P. A. Chiappori et al., forthcoming's analysis to a model where agents form couples with endogenously assigned roles according to their characteristics. The model is applied to team formation in professional road cycling. Fox, 2018 employs a very general many-to-many matching framework where agents self-select to be buyers or sellers upon a meeting. In both cases, hierarchy (leader vs assistants) or roles (buyers vs sellers) are clearly defined upon a match and observed in the data. This is unlikely to be the case when it comes to more complex and long-lasting relationships such as marriage.
} 
while the density of the characteristics among the population of women is $g$. In this setting, the set of feasible matchings is typically given by:

$$
\mathcal{M}(f, g)=\left\{\pi \geq 0:\left(\begin{array}{l}
\int_{\mathcal{X}} \pi(x, y) d y=f(x) \forall x \in \mathcal{X} \\
\int_{\mathcal{X}} \pi(x, y) d x=g(y) \forall y \in \mathcal{X}
\end{array}\right)\right\}
$$

Hence, $\pi \in \mathcal{M}^{\text {sym }}(f)$ if and only if $\pi \in \mathcal{M}(f, f)$ and $\pi\left(x_{1}, x_{2}\right)=\pi\left(x_{2}, x_{1}\right)$. Thus the feasibility set in the unipartite problem and in the bipartite problem differ only by the additional symmetry constraint in the unipartite problem.

2.2. Preferences. We now model preferences. Following DG, it is assumed that a given individual $x$ does not have access to the whole population, but only to a set of acquaintances $\left\{z_{k}^{x}: k \in \mathbb{Z}_{+}\right\}$, randomly drawn, which is described below.

Assumption 2 (Preferences). An individual of type $x$ matched to an individual of type $x^{\prime}$ enjoys a surplus which is the sum of three terms:

(i) the systematic part of the pre-transfer matching surplus enjoyed by $x$ from his/her match with $x^{\prime}$, denoted $\alpha\left(x, x^{\prime}\right)$.

(ii) an endogenous utility transfer from $x^{\prime}$ to $x$, denoted $\tau\left(x, x^{\prime}\right)$. This quantity can be either positive or negative; we assume utility is fully transferable, hence feasibility imposes $\tau\left(x, x^{\prime}\right)+$ $\tau\left(x^{\prime}, x\right)=0$.

(iii) a "sympathy shock" $(\sigma / 2) \varepsilon^{x}$, which is stochastic conditional on $x$ and $x^{\prime}$, and whose value is $-\infty$ if $x$ is not acquainted with an individual $x^{\prime}$. The quantity $\sigma / 2$ is simply a scaling factor. More precisely, the set of acquaintances is an infinite countable random subset of $\mathcal{X}$; it is such that $\left(z_{k}^{x}, \varepsilon_{k}^{x}\right)$ are the points of a Poisson process on $\mathcal{X} \times \mathbb{R}$ of intensity $d z \times e^{-\varepsilon} d \varepsilon$.

While the stochastic structure of the unobserved variation in preference described in part (iii) of Assumption 2 may appear complex, it is in fact a very natural extension of the logit framework to the continuous case, as we now argue. Indeed, it will imply that the individual maximization program of an agent of type $x$ with this set of acquaintances is

$$
\max _{k \in \mathbb{Z}_{+}} \alpha\left(x, z_{k}^{x}\right)+\tau\left(x, z_{k}^{x}\right)+\frac{\sigma}{2} \varepsilon_{k}^{x},
$$


where the utility of matching with acquaintance $k$ yields a total surplus which is the sum of three terms, the systematic pre-transfer surplus, the transfer, and the sympathy shock. Define the systematic quantity of surplus at equilibrium $U$ by

$$
U\left(x, x^{\prime}\right):=\alpha\left(x, x^{\prime}\right)+\tau\left(x, x^{\prime}\right)
$$

thus an individual of type $x$ maximizes $U\left(x, z_{k}^{x}\right)+(\sigma / 2) \varepsilon_{k}^{x}$ over the set of his/her acquaintances, which are indexed by $k$. This induces an aggregate demand over the type space. Indeed, it follows from the continuous logit theory initiated in Dagsvik, 1994 that the conditional probability density of an individual of type $x$ matching with a partner of type $x^{\prime}$ is

$$
\pi\left(x^{\prime} \mid x\right)=\frac{\exp \frac{U\left(x, x^{\prime}\right)}{\sigma / 2}}{\int_{\mathcal{X}} \exp \frac{U\left(x, x^{\prime}\right)}{\sigma / 2} d x^{\prime}} .
$$

It is clear from expression (2.2) that this is a generalization of the logit framework to the continuous case.

Note that, by the property of independence of irrelevant alternatives (IIA) of the logit model, we do not need to describe the utilities of unmatched agents as long as the distributions of their stochastic parts are assumed to remain in the logit setting. Indeed, in the dataset we use, all agents are matched. Of course, one may worry about a potential equilibrium selection issue, i.e., that being matched affects the distributions of the agents' unobserved heterogeneity; however, in the logit setting, the IIA property guarantees that the distributions are preserved even after the selection, as shown in appendix D of DG. This is the reason why we consider a model where everyone is matched at equilibrium.

2.3. Equilibrium. Next, we define equilibrium in this framework. Denote

$$
\Phi\left(x, x^{\prime}\right):=\alpha\left(x, x^{\prime}\right)+\alpha\left(x^{\prime}, x\right)=U\left(x, x^{\prime}\right)+U\left(x^{\prime}, x\right)
$$


the systematic part of the joint surplus ${ }^{8}$ between $x$ and $x^{\prime}$. It follows from (2.2) and symmetry of $\pi$ that

$$
\begin{gathered}
(\sigma / 2) \ln \pi\left(x, x^{\prime}\right)=U\left(x, x^{\prime}\right)-a(x)=U\left(x^{\prime}, x\right)-a\left(x^{\prime}\right), \\
\text { where } a(x) \quad: \quad=\frac{\sigma}{2} \log \int_{\mathcal{X}} \frac{1}{f(x)} \exp \frac{U\left(x, x^{\prime}\right)}{\sigma / 2} d x^{\prime} .
\end{gathered}
$$

Substituting out for $U$ in (2.3) yields the following equation, which expresses optimality in individual decisions:

$$
\log \pi\left(x, x^{\prime}\right)=\frac{\Phi\left(x, x^{\prime}\right)-a(x)-a\left(x^{\prime}\right)}{\sigma},
$$

At equilibrium, the value of $a($.$) is determined by market-clearing condition \int_{\mathcal{X}} \pi\left(x, x^{\prime}\right) d x^{\prime}=$ $f(x)$, that is

$$
\int_{\mathcal{X}} \exp \left(\frac{\Phi\left(x, x^{\prime}\right)-a(x)-a\left(x^{\prime}\right)}{\sigma}\right) d x^{\prime}=f(x) .
$$

We can now define our equilibrium matching concept.

Definition 1. The density $\pi$ is an equilibrium matching if and only if there is a function a (.) such that both optimality equations (2.5) and market clearing equations (2.6) are satisfied.

The main results on equilibrium characterization are summarized in the following statement:

Theorem A. Under Assumptions (1) and (2):

(i) The equilibrium matching $\pi\left(x, x^{\prime}\right)$ is the unique solution to

$$
\max _{\pi \in \mathcal{M}(f, f)} \iint_{\mathcal{X} \times \mathcal{X}} \Phi\left(x, x^{\prime}\right) \pi\left(x, x^{\prime}\right) d x d x^{\prime}-\sigma \mathcal{E}(\pi),
$$

where $\mathcal{E}(\pi)$ is defined by

$$
\mathcal{E}(\pi)=\iint_{\mathcal{X} \times \mathcal{X}} \pi\left(x, x^{\prime}\right) \ln \pi\left(x, x^{\prime}\right) d x d x^{\prime}
$$

(ii) The expression of $\pi\left(x, x^{\prime}\right)$ is given by

$$
\pi\left(x, x^{\prime}\right)=\exp \left(\frac{\Phi\left(x, x^{\prime}\right)-a(x)-a\left(x^{\prime}\right)}{\sigma}\right)
$$

\footnotetext{
${ }^{8}$ Note that $\Phi$ is symmetric by definition, but $\alpha$ has no reason to be symmetric. Mathematically speaking, $\Phi$ is (twice) the symmetric part of $\alpha$.
} 
where $a($.$) is a fixed point of F$, which is given by

$$
F[a](x)=\sigma \log \int_{\mathcal{X}} \exp \left(\frac{\Phi\left(x, x^{\prime}\right)-a\left(x^{\prime}\right)}{\sigma}\right) d x^{\prime}-\sigma \log f(x) .
$$

Proof. By DG, Theorem 1, Problem (2.7) has a unique solution which can be expressed as

$$
\pi\left(x, x^{\prime}\right)=\exp \left(\frac{\Phi\left(x, x^{\prime}\right)-a(x)-b\left(x^{\prime}\right)}{\sigma}\right)
$$

for some $a(x)$ and $b\left(x^{\prime}\right)$ determined by $\pi \in \mathcal{M}(f, f)$. By the symmetry of $\Phi$ and by the symmetry of the constraints implied by $\pi \in \mathcal{M}(f, f)$, then $\tilde{\pi}\left(x^{\prime}, x\right):=\pi\left(x, x^{\prime}\right)$ is also solution to (2.7). By uniqueness, $\tilde{\pi}=\pi$, thus $\pi\left(x, x^{\prime}\right)=\pi\left(x^{\prime}, x\right)$. As a result, $b(x)=a(x)$, where $a$ is determined by

$$
\int \exp \left(\frac{\Phi\left(x, x^{\prime}\right)-a(x)-a\left(x^{\prime}\right)}{\sigma}\right) d x^{\prime}=f(x)
$$

QED.

This result deserves a number of comments. First, we should note that there is an interesting interpretation of (2.7). While the first term inside the maximum tends to maximize the sum of the observable joint surplus, and hence draws the solution toward assortativeness, the second term $\mathcal{E}(\pi)$ is an entropic term which draws the solution toward randomness. The trade-off between assortativeness and randomness is expressed by the ratio $\Phi / \sigma$. If this ratio is large, the assortative term predominates, and the solution will be close to the assortative solution. If this ratio is small, the entropic term predominates, and the solution will be close to the random solution. At the same time, note that the model parameterized by $(\Phi, \sigma)$ is scale-invariant: if $k>0$, then the equilibrium matching distribution $\pi$ when the parameter is $(\Phi, \sigma)$ is unchanged when the parameter is $(k \Phi, k \sigma)$. This will have important consequences for identification, which is discussed in the next paragraph.

As a consequence of this result, we can deduce the equilibrium transfers and the utilities at equilibrium. Indeed, note that combining the expression of $\pi$ as a function of $U$ and $a$ and equation (2.5) yields the following expression of $U$ as a function of $a$ :

$$
U\left(x, x^{\prime}\right)=\left(\Phi\left(x, x^{\prime}\right)+a(x)-a\left(x^{\prime}\right)\right) / 2 .
$$

which is the systematic part of utility that an individual of type $x$ obtains at equilibrium from a match with an individual of type $x^{\prime}$. It is equal to half of the joint surplus, plus an adjustment 
$\left(a(x)-a\left(x^{\prime}\right)\right) / 2$ which reflects the relative bargaining powers of $x$ and $x^{\prime}$. These bargaining powers depend on the relative scarcity of their types; indeed, $a(x)$ is to be interpreted as the Lagrange multiplier of the scarcity constraint which imposes that $\pi(., x)$ should sum to $f(x)$. Hence, the equilibrium transfer $\tau\left(x, x^{\prime}\right)$ from $x$ to $x^{\prime}$ is given by

$$
\tau\left(x, x^{\prime}\right)=\left(\alpha\left(x^{\prime}, x\right)-\alpha\left(x, x^{\prime}\right)+a(x)-a\left(x^{\prime}\right)\right) / 2 .
$$

Next, note that an interesting feature of Theorem A is that, while it characterizes equilibrium in the same-sex marriage problem, it highlights at the same time the equivalence with the differentsex marriage problem: indeed, as argued in DG, Theorem 1, the equilibrium matching in the different-sex marriage problem is given by the same expression as (2.7), with the only difference that $\mathcal{M}(f, f)$ is replaced by $\mathcal{M}(f, g)$, where $f$ and $g$ are respectively the distribution of men and women's characteristics.

We will use this characterization of the equilibrium matching as the solution of an optimization problem in order to estimate the joint surplus $\Phi$ based on the observation of the matching density $\pi$. As it is classical in the literature on the estimation of matching models with transferable utility, the primitive object of our investigations will be the joint surplus $\Phi$ rather than the individual pre-transfer surplus $\alpha$; indeed, without observations on the transfers, there is no hope to identify $\alpha$ : if we estimate that there is a high level of joint surplus in the $\left(x, x^{\prime}\right)$ relationship, we will not be able to determine if this is due to the fact that " $x$ likes $x^{\prime \prime}$ or " $x$ ' likes $x$ ". We will only be able to estimate that there is a high affinity between $x$ and $x^{\prime}$.

\section{Estimation}

3.1. Estimation of the affinity matrix. Following DG, we assume a quadratic parametrization of the surplus function $\Phi$ to focus on a limited number of parameters which could characterize the matching patterns. We parametrize $\Phi$ by an affinity matrix $A$ so that

$$
\Phi_{A}(x, y)=x^{\prime} A y=\sum_{i j} A_{i j} x^{i} y^{j}
$$


where $A$ has to be symmetric $\left(A_{i j}=A_{j i}\right)$ in order for $\Phi$ to satisfy the symmetry requirement. Then the coefficients of the affinity matrix are given by $A_{i j}=\partial^{2} \Phi(x, y) / \partial x^{i} \partial y^{j}$ at any value $(x, y)$. Matrix $A$ has a straightforward interpretation: $A_{i j}$ is the marginal increase (or decrease, according to the sign) in the joint surplus resulting from a one-unit increase in the attribute $i$ for the first partner, in conjunction with a one-unit increase in the attribute $j$ for the second. Hence, this approach is arguably the most straightforward way to model pairwise positive or negative complementarities for any pair of characteristics. It does, however, not preclude nonlinear functions of the $x_{i}$ 's and the $y_{j}$ 's, which can always be appended to $x$ and $y$.

Recall equation (2.7), the optimal matching $\pi$ maximizes the social gain

$$
\mathcal{W}(A)=\max _{\pi \in \mathcal{M}(f, f)} \mathbb{E}_{\pi}\left[x^{\prime} A y\right]-\sigma \mathbb{E}_{\pi}[\ln \pi(x, y)]
$$

which yields likelihood $\pi^{A}\left(x, x^{\prime}\right)$ of observation $\left(x, x^{\prime}\right)$, where $\pi^{A}$ is the solution to (3.1). By the envelope theorem, $\partial \mathcal{W}(A) / \partial A_{i j}=\mathbb{E}_{\pi^{A}}\left[x^{i} y^{j}\right]$. Hence, our empirical strategy is to look for $\hat{A}$ satisfying

$$
\partial \mathcal{W}(\hat{A}) / \partial A_{i j}=\mathbb{E}_{\hat{\pi}}\left[x^{i} y^{j}\right]
$$

where $\hat{\pi}$ is empirical distribution associated with the observed matching.

As noted before, the model with parameters $(A, \sigma)$ is equivalent to the model with parameters $(k A, k \sigma)$ for $k>0$. Hence, a choice of scale normalization should be imposed without loss of generality; a simple choice when a single market is considered is $\sigma=1$, in which case the estimator $A$ is meant as the estimator of the ratio of the affinity matrix over the scale parameter. The observation and comparison of multiple markets lead to slightly different normalization choices, which are discussed in section 3.5.

If a sample of size $n,\left\{\left(x_{1}, y_{1}\right), \ldots,\left(x_{n}, y_{n}\right)\right\}$ is observed, then $\hat{\pi}(x, y)$ is the associated empirical distribution, which places mass $1 / n$ to each observation. In DG, an estimator of $A$ is obtained by solving the following concave optimization problem

$$
\min _{A \in M_{K}} \mathcal{W}(A)-\mathbb{E}_{\hat{\pi}}\left[\sum_{i j} A_{i j} x^{i} y^{j}\right]
$$


where $M_{K}$ is the set of real $K \times K$ matrices. Indeed, the first order conditions associated to (3.3) are exactly given by (3.2). However, in the present case, the symmetry of $A$ is a requirement of the model. The population cross-covariance matrix $\mathbb{E}_{\pi}\left[x^{i} y^{j}\right]$ is symmetric, as $\pi$ satisfies the symmetry restriction $\pi(x, y)=\pi(y, x)$ in the population. Yet, in the sample, $\hat{\pi}$ has no reason to be symmetric, as the first vector of variables $x$ typically designates the surveyed individual, while the second vector of variables $y$ designates the partner of the surveyed individual. Hence, the empirical matrix of covariances $\mathbb{E}_{\hat{\pi}}\left[x^{i} y^{j}\right]$ will only be approximately symmetric. Thus, we symmetrize the sample by adding the symmetric households, that is, if household $i j$ is included, meaning that individual $i$ was surveyed and reported partner $j$, we add a symmetric household $j i$, with $j$ surveyed and reporting partner $i$. In other words, we replace the empirical distribution $\hat{\pi}\left(x, x^{\prime}\right)$ by its symmetric part $\left(\hat{\pi}\left(x, x^{\prime}\right)+\hat{\pi}\left(x^{\prime}, x\right)\right) / 2$. In the sequel, $\hat{\pi}$ will denote that symmetric part. This leads us to propose the following definition:

Definition 2. The estimator $\hat{A}$ of the affinity matrix is obtained by

$$
\hat{A}=\arg \min _{A \in M_{K}}\left\{\mathcal{W}(A)-\mathbb{E}_{\hat{\pi}}\left[\sum_{1 \leq i, j \leq K} A_{i j} X^{i} Y^{j}\right]\right\}
$$

where $M_{K}$ is the set of real $K \times K$ matrices.

The asymptotic behaviour of $\hat{A}$ is computed in DG, theorem 2. A word of caution, is, however, in order. Although we have artificially doubled the sample size, by complementing household $\left(x_{i}, y_{i}\right)$ with its mirror image $\left(y_{i}, x_{i}\right)$, one should beware that the sample size remains $n$, not $2 n$. Thus, we can use directly the bipartite estimator on the mirrored sample, with the only modification that one will need to multiply the standard errors by a factor $\sqrt{2}$, as the effective sample size has not doubled.

3.2. Categorical variables. The previous analysis can be slightly adapted to deal with the case of categorical variables, such as race. Assume that the set of categories is denoted $\mathcal{R}=\{1, \ldots, r\}$. Assume that the individuals are characterized by $x=\left(x^{S}, x^{R}\right)$, where $x^{S} \in \mathbb{R}^{K}$ are socio-economic characteristics, and $x^{R} \in \mathbb{R}^{r}$ is a vector of dummy variables $x_{i}^{R}(1 \leq i \leq r)$ equal to 1 if individual $x$ is of category $i \in\{1, \ldots, r\}$, and zero otherwise. We work with the following specification of the surplus

$$
\Phi(x, y)=\left(x^{S}\right)^{\prime} A^{S} y^{S}+\lambda_{R} 1\left\{x^{R}=y^{R}\right\}
$$


where $\lambda_{R}$ is a term that reflects assortativeness on the categorical variable, which provides a utility increment $\lambda_{R}$ if both partners belong to the same category. Of course, this surplus function can be expressed multiplicatively as $\Phi(x, y)=x^{\prime} A y$, where $A$ can be written blockwise as

$$
A=\left(\begin{array}{cc}
A^{S} & 0 \\
0 & \lambda_{R} I_{r}
\end{array}\right)
$$

and hence, $A$ is obtained by running optimization problem (3.4) subject to constraint (3.6). Note that the envelope theorem implies that $\lambda_{R}$ is identified by the moment matching condition

$$
\operatorname{Pr}_{\pi}\left(x^{R}=y^{R}\right)=\operatorname{Pr}_{\hat{\pi}}\left(x^{R}=y^{R}\right)
$$

which states that the predicted frequency of interracial couples should match the observed one.

3.3. Saliency analysis. The rank of the affinity matrix is informative about the dimensionality of the problem, that is, how many indices are needed to explain the sorting in this market. To answer this question, DG introduced saliency analysis, which consists of looking for successive approximations of the $K$-dimensional matching market by $p$-dimensional matching markets $(p \leq$ $K)$. Assume (without loss of generality as one can always rescale) that $\operatorname{var}\left(X_{i}\right)=\operatorname{var}\left(Y_{j}\right)=1$. Then saliency analysis consists of a singular value decomposition of the affinity matrix $A=U^{\prime} \Lambda V$, where $U$ and $V$ are orthogonal loading matrices, and $\Lambda$ is diagonal with positive and decreasing coefficients on the diagonal. This idea is found in Heckman, 2007, who interprets the assignment matrix as a sum of Cobb-Douglas technologies using a singular value decomposition in order to refine bounds on wages. This allows to introduce new indices $\tilde{x}=U x$ and $\tilde{y}=V y$ which are orthogonal transforms of the former, and such that the joint surplus reflects diagonal interactions of the new indices, i.e. $\Phi(x, y)=x^{\prime} U^{\prime} \Lambda V y=\tilde{x} \Lambda \tilde{y}$.

Here, we need to slightly adapt this idea to take advantage of the symmetry of $A$ and of the requirement that the matrix of loadings $U$ and $V$ should be identical. The natural solution is the eigenvalue decomposition of $A$, which leads to the existence of an orthogonal loading matrix $U$ and a diagonal $\Lambda=\operatorname{diag}\left(\lambda_{i}\right)$ with non-increasing (but not necessarily positive) coefficients on the diagonal such that

$$
A=U^{\prime} \Lambda U
$$


This allows us to introduce a new vector of indices $\tilde{x}=U x$, which are orthogonal transforms of the previous indices. That way, the joint surplus between individuals $x$ and $y$ is given by

$$
\Phi(x, y)=x^{\prime} U^{\prime} \Lambda U y=\tilde{x}^{\prime} \Lambda \tilde{y}=\sum_{p=1}^{K} \lambda_{p} \tilde{x}^{p} \tilde{y}^{p}
$$

hence this term only reflects pairwise interactions of dimension $p$ of $\tilde{x}$ and $\tilde{y}$, which are either complements (if $\lambda_{p}>0$ ) or substitute (if $\lambda_{p}<0$ ), and there are no complementarities across different dimensions.

The following statement formalizes this finding:

Theorem B. Assume that $\mathbb{E}_{\hat{\pi}}[X]=0$ and that $\operatorname{var}_{\hat{\pi}}\left(X^{i}\right)=1$ for all $i$. Then there exists an orthogonal loading matrix $\hat{U}$ and a diagonal $\hat{\Lambda}=\operatorname{diag}\left(\lambda_{i}\right)$ with non-increasing coefficients on the diagonal such that

$$
\hat{A}=\hat{U}^{\prime} \hat{\Lambda} \hat{U}
$$

and, denoting $\tilde{x}=\hat{U} x$ and $\tilde{y}=\hat{U} y$, the estimator of the surplus function is given by

$$
\hat{\Phi}(x, y)=\tilde{x}^{\prime} \hat{\Lambda} \tilde{y}=\sum_{p=1}^{K} \lambda_{p} \tilde{x}^{p} \tilde{y}^{p} .
$$

Proof. Because $\hat{A}$ is symmetric, it has the following eigenvalue decomposition

$$
\hat{A}=\hat{U}^{\prime} \hat{\Lambda} \hat{U}
$$

where $\hat{U}$ is orthogonal, and $\hat{\Lambda}=\operatorname{diag}\left(\lambda_{i}\right)$ is diagonal with non-increasing coefficients. Denoting $\tilde{x}=\hat{U} x$ and $\tilde{y}=\hat{U} y$,

$$
x^{\prime} A y=x^{\prime} \hat{U}^{\prime} \hat{\Lambda} \hat{U} y=\tilde{x}^{\prime} \hat{\Lambda} \tilde{y}=\sum_{p=1}^{K} \lambda_{p} \tilde{x}^{p} \tilde{y}^{p} .
$$

In the presence of categorical variables, the presence of a block $\lambda I_{r}$ in (3.6) reflecting assortativeness on the categorical variable implies that the singular values of $A$ will be the singular values of $\tilde{A}$ in addition to $\lambda$ with multiplicity $r$. Therefore, it is recommended to perform saliency analysis simply on the upper left block $\tilde{A}$. 
3.4. Selection issues. The purpose of the present paper is to compare match formation across same-sex and different-sex marriage market using the tools we developed above. In order to do so, we need to clearly delineate what is the relevant market in which agents match. We make the following assumption that gay men, lesbians and heterosexuals match on segmented markets, which we formalize into:

Assumption 3 (Exogenous selection). The selection into either the same-sex or different-sex marriage market is exogenous.

To relax this assumption, one would have to assume that all agents are pooled together in the same market, and choose their partner's gender among other characteristics, based on their own sexual orientation. The marital outcome, including the gender composition of households, would then be an equilibrium outcome resulting from a trade-off between socio-economic complementarities and other terms reflecting interactions between genders, and sexual orientations of the partners. We develop and discuss this relaxed framework in appendix A, which shows that the market can be formulated as a single unipartite one where individuals are characterized by sexual orientation and gender in addition to other socioeconomic traits, and choose the gender of their partners among other characteristics. The more restrictive framework provided by assumption 3 can be obtained as a limiting case of the single-market framework where the interaction between sexual orientation and gender is predominant with respect to other characteristics, and thus the partner's gender is fully determined by own sexual orientation and gender.

In the absence of data on sexual orientation in our database, assumption 3 allows to infer sexual orientation from market participation, and therefore it permits to perform estimation of the affinity matrix expressing the interactions of the socioeconomic characteristics. However, if data on socioeconomic characteristics, gender and sexual orientation of matched partners were available, then the full matrix $A$ could be estimated in a straightforward manner using our methodology, allowing to capture interactions not only between socio-economic terms, but also between gender and sexual orientation, etc., as explained in appendix $\mathrm{A}^{9}$.

\footnotetext{
${ }^{9}$ While this may be out of reach with current large-scale datasets, it is not unrealistic to believe that it will be possible to perform this type of analysis in the future. The National Survey of Family Growth, for instance, already
} 
As a final remark, the very fact that sexual orientation is exogenous is itself a strong assumption, and subject to current scientific debate. Researchers in biology, neuroscience, sexual medicine and psychology have provided evidence on the influence of psycho-biological mechanisms on homosexual orientation (see Hines, 2011; Jannini et al., 2010). While there is an open debate among psychologists and social scientists about the stability of sexual behaviour ${ }^{10}$, research on early learning during childhood suggests that gender-typed behaviour -including sexual attraction- is internalized since infancy and stabilizes by late adolescence (see Dillon et al., 2011; Hines, 2011).

3.5. Comparison across markets. Affinity matrices are a useful tool to analyze marital surplus, and we would like to use them to compare sorting patterns across different-sex and female/male same-sex marriage markets. However, in order to achieve this, a discussion on normalization is needed. Indeed, recall from the above discussion that the equilibrium matching $\pi$ is the solution to

$$
\mathcal{W}(A, \sigma)=\max _{\pi \in \mathcal{M}(f, f)}\left\{\mathbb{E}_{\pi}\left[X^{\prime} A Y\right]-\sigma \mathbb{E}_{\pi}[\ln \pi(X, Y)]\right\},
$$

and therefore, a matching market with affinity matrix $A$ and scaling parameter $\sigma$ is observationally equivalent to another market with the same distribution of types and affinity matrix $k A$ and scaling parameter $k \sigma$ for $k>0$. Therefore, $A$ and $\sigma$ are not jointly identified, but only their ratio $A / \sigma$ is identified.

It is therefore useful to adopt a normalization of $(A, \sigma)$. For cross-market comparison purposes, the normalization $\sigma=1$ advocated in DG can be misleading, as it assumes that the standard deviation of the heterogeneity in preferences is the same across all markets considered. In this case, it seems more appropriate to normalize $A$ by a factor so that the total quantity of surplus $\mathcal{W}(A, \sigma)$ is scaled to one in each market. That is:

Assumption 4. The affinity matrix $A$ and the amount of heterogeneity $\sigma$ are normalized so that the equality $\mathcal{W}(A, \sigma)=1$ holds in each market.

contains detailed data on this topic, but unfortunately has no information on same-sex partnerships. This is due to the latter being recognized at federal level only recently.

${ }^{10}$ Diamond, 2008a have provided the first piece of quantitative of the fluctuations of sexual orientation among adults women using long panel data. However, psychologists avoid talking about sexuality as a "choice of lifestyle": Diamond, 2008b, Chapter 5 considers changes in sexual orientation - and in other aspects of sexuality - as the consequence of "complex interplays among biological, environmental, psychological, and interpersonal factors". 
When considering a single market, assumption 4 is a mere normalization, which can be imposed without loss of generality. It implies that the ratio of the average surplus provided by the interaction between characteristics $i$ and $j$ of two partners in a given market, divided by the average total surplus of a couple in that market is given by

$$
\frac{A_{i j} \mathbb{E}\left[X^{i} Y^{j}\right]}{\mathcal{W}(A, \sigma)}=A_{i j} \mathbb{E}\left[X^{i} Y^{j}\right],
$$

and hence $A_{i j} \mathbb{E}\left[X^{i} Y^{j}\right]$ is the share of the average surplus explained by the interaction between characteristics $i$ and $j$, relative to the average total surplus of a couple in that market.

On the contrary, when considering multiple markets, assumption 4 is no longer an innocuous normalization. It allows for a direct comparison of affinity matrices across markets, if one is willing to make the restrictive assumption that the average surplus of a couple is the same in every market. Note that, since $\mathcal{W}(k A, k)=k \mathcal{W}(A, 1)$ holds for any scaling parameter $k \geq 0$, in practice, we impose this normalization by first computing the estimator $\hat{A}$ given by (3.4), and we then report $\hat{A} / \mathcal{W}(\hat{A}, 1)$.

\section{DATA}

4.1. Data on same-sex couples. Empirical studies on same-sex marriage have traditionally needed to cope with poor data, due to the late legal recognition of these partnerships - still unachieved in several countries - and with misreporting issues, due to social pressure on respondents. Social scientists have largely relied on the data collected by the US Census Bureau for large sample analysis of same-sex unions (D. A. Black et al., 2007; L. K. Jepsen \& Jepsen, 2002; Schwartz \& Graf, 2009). Starting from the 1990 decennial census, individuals could report themselves as "unmarried partners" within the household, regardless of their sex, so that gay couples could be identified. In more recent databases from the US Census Bureau, same-sex couples are still identifiable as out-of-marriage cohabiting partners. Indeed, although same-sex marriages have been officiated in some American states since 2004, they were recognized at federal level only in 2013, and currently available surveys conducted until then by the Census Bureau have not allowed reporting marriage bonds other than different-sex unions.

Accordingly, the present work relies on the five-year Public Use Microdata Sample (PUMS) for 2008-2012 coming from the ACS, conducted by the US Census Bureau. We restricted our sample 
to the state of California, which first legalized same-sex marriage on June 16, 2008 following a Supreme Court of California decision, and then - after some judicial and political controversies that impeded the officialization of same-sex weddings from November 5, 2008 to June 28, $2013^{11}$ a decision of the U.S. Supreme Court finally accomplished full legalization. Restricting the sample to one state allows focusing on a marriage market with a uniform judicial framework. Moreover, in states where same-sex marriage is recognized, estimates on the number of married same-sex households are more reliable, and the incidence of the measurement error is smaller (Gates, 2010; Virgile, 2011).

4.2. Descriptive statistics. Our sample is limited to those individuals involved in a cohabiting partnership, both married and unmarried, thus excluding singles but also couples whose partners do not live in the same home. Each couple is identified as a householder with his/her partner, where both share the same ID household number.

The main database is composed of 681,060 individuals in couples who have completed their schooling. Because we restrict ourselves to prime age couples (both partners 25-50 year old), the size of our sample is decreased to 285,546 individuals. Out of them, 3,654 individuals $(1.28 \%$ of the sample) live in same-sex couples, of which 2,034 male (0.71\%) and 1,620 female (0.57\%). 87.39\% of the individuals in the sample are married heterosexuals and $11.33 \%$ are cohabiting heterosexuals. For estimation purposes, after randomly selecting a subsample of different-sex couples ${ }^{12}$, a total of 9,820 couples are considered, of which 4,959 are married and 4,799 are not.

To compare different marriage markets, following (L. K. Jepsen \& Jepsen, 2002), the main sample is divided into four subsamples: same-sex male couples, same-sex female couples, different-sex unmarried couples and different-sex married couples. This repartition is based on the assumption that individuals enter into separate markets according to their sexuality, in line with assumption 3. However, another criterion is used to differentiate two of the subgroups: married and unmarried different-sex couples are treated as two separate subpopulations ${ }^{13}$, since empirical evidence has reported significant differences in patterns between these two kinds of partnership (L. K. Jepsen

\footnotetext{
${ }^{11}$ In this period, marriage licenses issued to same-sex couples held their validity.

${ }^{12}$ We randomly select $4 \%$ of married couples and $30 \%$ of unmarried couples.

${ }^{13}$ See Mourifié and Siow, 2014 for a very interesting discussion of the endogenous choice of the form of marital relationship.
} 
\& Jepsen, 2002; Schwartz \& Graf, 2009). Although it is impossible to know a priori if a person is interested in a marital union rather than in a less binding relationship, this repartition can be of great interest and deepen the analysis. Nevertheless, even if California represents the larger state-level ACS sample in the US, further splitting the gay and lesbian groups into two subgroups would imply working with potentially very small samples. Moreover, although same-sex marriage is permitted, it has been recognized only recently and at the end of many legal struggles, which may have prevented a part of those same-sex couples that wished to marry from doing so. With more data available, considering married and unmarried same-sex couples separately would be extremely interesting, as proved by recent research of (Verbakel \& Kalmijn, 2014) based on Dutch data.

Our study takes into consideration several variables, some related to the labor market and some others to the general background. Non-labor market traits include age, education and race. Age and education are treated as continuous variables, with the latter defined as the highest schooling level attained by the individual. Thanks to the detailed data of the ACS, the variable has been built in order to reflect as many distinct educational stages as possible. We consider five large racial/ethnic groups: Non-Hispanic White, Non-Hispanic Black, Non-Hispanic Asian, Hispanic and Others $^{14}$. Finally, among labor market variables, we compute and include hourly wage ${ }^{15}$ and usual amount of hours worked per week. Note that yearly wage is top-coded for very high values (over $\$ 999,999)$.

Table 1 presents some descriptive statistics of our sample. Individuals in same-sex couples are on average more educated than individuals in opposite-sex couples. As observed by (D. A. Black et al., 2007), lesbians are much more likely to be part of the labor force than women in different-sex

\footnotetext{
${ }^{14}$ American demographic institutions do not include a Hispanic category in variables on race, furnishing a separate variable for Hispanic origins, which is why there is some overlapping and the other categories bear the specification "Non-Hispanic". The issue concerns the conceptual differences of "race" and "ethnicity". See for instance (Rodriguez, 2000) for clarifications.

${ }^{15}$ The variable is computed as follows: we divide yearly wage by 52 in order to have the average weekly wage for last year and then we divide it again by the usual number of hours worked per week, which is available in the dataset. The hourly wage is partly approximated because the exact number of weeks worked in the last 12 months is not available. Note also that when information on labor earning or number of working weeks is missing, we set the hourly wage and the number of working weeks to 0 so that we keep all individuals in our analysis.
} 
couples, and also have higher wages. We observe that unmarried different-sex couples are much younger than married couples and same-sex couples. Unmarried heterosexual men and women are on average four year younger than others. Cohabitation is often (but not always) a "trial" period before marriage, which can explain this age difference ${ }^{16}$. Table 2 presents the distribution of ethnicity among couples: White individuals and Black women are overrepresented among lesbians, while Asians and Hispanics are under-represented in this population.

Table 3 presents correlations among traits. It shows that age and educational attainment are much more correlated among married different-sex couples than among unmarried and same-sex ones. Moreover, the correlation is stronger for lesbian couples than for gay male ones. Correlations on labor market outcomes are particularly interesting: hours worked are negatively correlated only for married different-sex couples, a possible clue of stronger household specialization, whereas the correlation is positive albeit low for same-sex couples. On the other hand, wages display a positive correlation in every market, with different-sex married couples and male same-sex couples exhibiting the lowest correlation.

Table 4a, 4b and 4c present homogamy rates of couples with respect to race for different types of couples. The homogamy rate is the ratio between the observed number of couples of a certain type and the counterfactual number which should be observed if individuals formed couples randomly. For instance, table 4b shows that lesbian couples among Black women form 10 times much more than if they were formed randomly among the lesbian population.

\section{Results}

Homogamy rates and correlations presented in section 4 are interesting measures of assortative mating and provide a good starting point for our analysis. However, they are not sufficient to reach any conclusion about the degree of assortativeness in the marriage market. By estimating the parameters of the surplus function, we compare the level of complementarity and substitutability between characteristics across different marriage markets. This approach is consistent with Becker's model of assortative mating, and allows us to measure the degree of assortativeness for each combination of characteristics ceteris paribus. In particular, we can test whether assortativeness on

\footnotetext{
${ }^{16}$ This would require a dynamic framework, which we don't have in our static model. See the theoretical work of Brien et al., 2006 and Gemici and Laufer, 2011.
} 
observables - notably, age, race and education - is weaker among same-sex couples, as found by Schwartz and Graf, 2009.

While we measure the direction and strength of interactions between traits, we do not attempt to estimate preference and production terms separately. Hence, we cannot tell whether marital gains differ across markets because of differences in household production rather than pure taste for homogamy. In particular, we cannot tell to which extent differences in the opportunity cost of bearing and raising children affect sorting patterns ${ }^{17}$. If couples wish to have genetically related children, Assisted Reproductive Technologies imply that children inherit genetic traits from only one out of two partners, with possibly important implications for sorting. In our empirical analysis, we limit ourselves to the estimation of the model on carefully chosen subsamples (e.g., childless couples) in order to provide an intuition of where the major sources of diversity between gay and different-sex couples lie. While not exhaustive, these robustness checks could constitute a useful starting point for future research.

Finally, Becker's model suggests that we interpret differences in assortativeness as a consequence of differences in marital gains, rather than as a consequence of search dynamics (notably, geographic factors and search frictions), segmentation into local markets along socio-economic traits, or preferences of third parties and social pressure (Kalmijn, 1998). In particular, gay individuals tend to move away from their hometowns and may not be "out" at school or in the workplace (Rosenfeld \& Kim, 2005), and this could influence the composition of their interpersonal ties ${ }^{18}$. Also in this case, some of our robustness checks can help understand how these concurrent forces affect our results. Nonetheless, we believe that a model explicitly accounting for such factors would be necessary to quantify their impact on sorting patterns.

\footnotetext{
${ }^{17}$ Allen and $\mathrm{Lu}, 2017$ propose a theoretical model which explains differences in expected matching behavior, marriage rates, non-child-friendly activities, and fertility, based on different costs of procreation and complementarities between marriage and children.

${ }^{18}$ For instance, online dating among heterosexuals has been found to reduce assortative matching on education (Hitsch et al., 2010). However, as dating apps and websites grow in popularity, thus giving access to a larger and larger pool of possible matches, and tend to specialize on segmented markets (e.g., by ethnicity or religion), we wonder if this conclusion still holds.
} 
We report in table 5 the estimates of the affinity matrix for gays, lesbians, married and cohabiting heterosexuals.

5.1. Age, education and race/ethnicity. Our estimates of the diagonal elements of the affinity matrices are highly positive and significant for age, education and ethnicity, which confirms previous findings about positive assortative mating. In line with the results by L. K. Jepsen and Jepsen, 2002 and Schwartz and Graf, 2009, we find that assortativeness on age and ethnicity is comparatively weak for male same-sex couples (0.62 for age, 0.62 for ethnicity), and progressively stronger for female same-sex $(0.79,1.26)$ and unmarried different-sex couples $(1.14,1.98)$, whereas married different-sex couples exhibit the strongest complementarities $(2.17,2.49)$. Results on education are more nuanced: complementarity of schooling levels is the strongest for lesbian couples (1.19), while estimates for married same-sex (0.82) and gay couples (0.84) are not significantly different. Finally, complementarity of schooling levels is the lowest for unmarried heterosexuals (0.66).

Our estimates on the level of educational sorting is partly at odds with previous findings. Empirical research on this topic mainly concluded that assortativeness on education is weaker on both male and female same-sex marriage markets with respect to different-sex marriage markets. However, the social science literature ${ }^{19}$ provides a large set of explanations about why sorting patterns should differ across different-sex and same-sex couples, and not all of them predict that educational sorting is weaker among the latter. On the one hand, gay men and lesbians are expected to be more inclined to "transgress" social norms and to cross socio-economic and racial barriers when choosing their partner (Rosenfeld \& Kim, 2005; Schwartz \& Graf, 2009). Our findings suggest that this effect might be prevalent as concerns age and ethnicity. On the other hand, gay people are also expected to have stronger egalitarian preferences. Verbakel and Kalmijn, 2014 suggest that similar schooling levels can lead to a more equal division of labor. Spouses that aim to concentrate their efforts on the labor market rather than to specialize each in a different set of skills might thus exhibit a stronger level of assortativeness on education.

\footnotetext{
${ }^{19}$ The main reference works about mating among gay people are listed in our introduction. We refer to Schwartz and Graf, 2009 and Verbakel and Kalmijn, 2014 who, drawing from literatures from different social sciences, both provide a complete and updated review on this topic.
} 
As anticipated above, childrearing is a major driver of household specialization, and same-sex couples are less likely to have children ${ }^{20}$. Hence, we estimate the affinity matrix using the subsample of childless couples for each of our four marriage markets ${ }^{21}$ (see summary table 8 and the full tables in the online appendix). We find that, with respect to ethnicity, both childless same-sex and childless different-sex couples exhibit a weaker taste for homogamy compared with couples with children of the same respective sexual orientation. Similar results hold for sorting on age, although only differences between married different-sex couples with and without children are significantly different. It thus seems that individuals who plan to have children look for a more similar partner along these two dimensions than those who do not.

When it comes to education, the picture is a bit more contrasted. As for the previously discussed traits, one observes stronger assortativeness on education for same-sex couples with children than for those without. In contrast, childless different-sex couples are more assortatively matched on education than those with children. Different-sex couples who do not plan to have children will not benefit from large gains from specialization and may look for a partner with similar schooling. It is interesting to note that married childless different-sex couples are found to exhibit a higher degree of assortativeness with respect to age, ethnicity and education with respect to same-sex childless couples $^{22}$.

5.2. Labor market traits. To describe labor market traits, we must be very cautious as these outcomes are potentially endogenous. Since we do not observe these traits at the moment of the match formation but possibly much later, the specialization process at work in couples may have

\footnotetext{
${ }^{20}$ In our sample, among the $25-50$ years-old, $14.5 \%$ of gay men have children, $37.8 \%$ of lesbians, $58.04 \%$ of cohabiting different-sex couples and $83.5 \%$ of married different sex couples.

${ }^{21}$ We are aware that the subsample constitutes an "artificial" marriage market, since individuals do not rigidly self-select into a separate market based on their preference for having children. However, our model does not have a specification that explicitly accounts for choices related to childbearing.

${ }^{22}$ We also estimate the affinity matrix for married different-sex couples with one and three children (see table $8 \mathrm{c}$ ). Our findings are in line with what stated in the main text. The higher the number of children, the stronger the assortativeness on age and ethnicity, and the weaker the assortativeness on education.
} 
already begun. In particular, we expect that this specialization effect is strong in different-sex couples, who are more likely to have children ${ }^{23}$. Raising children takes time and many mothers leave the labor force or reduce their working hours. Consequently, because of interrupted careers and less paid part-time jobs, their hourly wage does not rise as much as that of their male counterparts and we observe many associations between low-wage women and high-wage men. This phenomenon could bias our estimates. To assess the importance and the sign of this bias, we also perform the estimation on four additional selected samples where the specialization effect should be limited : 1) childless couples, 2) bi-earner couples, 3) young couples (25-35 year old), 4) recently married couples with no children. The last selection is only available for different-sex married couples as we observe their wedding date; we keep couples who got married in the preceding year and who have no children. A summary of the results is available in tables $8 \mathrm{a}, 8 \mathrm{~b}, 8 \mathrm{c}$ and $8 \mathrm{~d}$. The full tables are available in the online appendix. We first describe the general results obtained from the main sample.

First, we measure significant positive assortativeness on hourly wages for all types of couples, although the coefficient is higher for same-sex couples (0.05 for gays and 0.06 for lesbians) and for different-sex unmarried couples (0.05) than for married different-sex couples (0.01). Furthermore, we observe negative assortative mating on working hours for married different-sex couples (-0.04), whereas we observe much higher and significant positive estimates for same-sex couples (0.12 for gays and 0.20 for lesbians). The coefficient for unmarried couples is also positive and significant (0.09). Assortative mating on wages and working hours is likely to be related to the presence of children. As same-sex couples are less likely to have children, they have weaker incentives for specialization. Unmarried couples may also have lower preferences for children than married couples. To better understand this result, we estimate our model on childless couples. We find that married different-sex couples without children have a positive coefficient for both wage (0.07) and working hours (0.12), and thus are more similar to same-sex and different-sex unmarried couples. In this regard, our results are in line with those of C. Jepsen and Jepsen, 2015. Similarly, the

\footnotetext{
${ }^{23}$ (Antecol \& Steinberger, 2013) and (C. Jepsen \& Jepsen, 2015) showed that to a lesser extent some household specialization also exists within same-sex households. Moreover, Antecol and Steinberger, 2013 stress that childless different-sex couples are less specialized and thus more similar to same-sex couples.
} 
assortative mating coefficients for wages and hours are higher - but to a lesser extent - for samesex couples without children compared to those with children. We also perform the estimation on married couples with only one child and married couples with three children to disentangle the effect of the presence of children among married couples. As couples have more children, we observe a decrease in assortative mating coefficients for wages and hours. Similarly, as expected, the estimation on bi-earner couples shows an increase in assortative mating on wages and hours ${ }^{24}$. In the case of young same-sex couples the comparison leads to less clear-cut conclusions due to small sample size, while positive assortative mating on labor market traits is stronger when comparing young different-sex couples with those in our main sample.

The cross-estimate between the wage of one partner and working hours of the other partner is also very interesting to analyze. We find negative assortative mating on wages and working hours. The estimate is highly negative for lesbians (-0.19) and different-sex married couples (-0.09 for the interaction between wife's wage and husband's hours, -0.13 for the symmetric interaction). It is also negative and significant for gays (-0.07). Hence, for heterosexual married couples and homosexual couples, the match gain increases when one partner increases his/her wage and the other decreases his/her working hours. This result is robust to the presence of children, to the age of couples and to the bi-earner sample.

5.3. Other cross-interactions and symmetry. Other significant positive cross-effects have been found for some off-diagonal elements of the affinity matrix. The parameter capturing the interaction between wage and education is persistently high and positive. This might suggest that higher wage individuals have a preference for more educated partners, keeping constant their wage and all other characteristics. Affinity between these two variables is relatively weaker for gay men (0.13) and lesbians (0.20). Complementarity between the two inputs is stronger for different-sex couples, but the relationship is asymmetric: estimates for married couples suggest that complementarity in husband's wage and wife's education is stronger (0.27) than the other way around (0.19). However, the corresponding estimates for unmarried couples go in the opposite direction ( 0.21 and 0.37 respectively). The complementarity between the two traits might be explained by the fact that

\footnotetext{
${ }^{24}$ In our analysis, bi-earner couples are couples whose both members declare positive wage and number of working weeks.
} 
high-income individuals - independently of their educational level - may enjoy the company of cultured partners.

Another cross-interaction that arises from the estimation is the substitutability between age and hours worked on same-sex marriage markets (-0.13 for gay men and -0.10 for lesbians). This interaction might be due to household bargaining dynamics, as explained by Oreffice, 2011: younger partners enjoy higher bargaining power and thus can afford reducing their labor supply. Interestingly, unmarried different-sex couples exhibit similar patterns, although the effect is weaker.

Finally, as a last robustness check for our main results, we estimate a bipartite matching model of the same-sex marriage market where the affinity matrix is not required to be symmetric. In this case, we need to define two separate subpopulations to run a bipartite estimation, and therefore we need to define household roles. On one side of the market, we group all those partners that are registered as "householders", whereas on the other we group their "cohabiting partners". This repartition is highly artificial, since it implies that two gay individuals that are householders before finding a partner can never match: in general, it seems implausible to divide the same-sex population in two separate subgroups with the data that we have at hand. Nonetheless, it is interesting to check under the strict assumption of predetermined roles - whether some asymmetry in cross-interactions occurs. We observe that the affinity matrices for both gay men and lesbians (respectively tables $7 \mathrm{a}$ and $7 \mathrm{~b}$ ) are not much different than in the unipartite case. When testing for differences between the off-diagonal coefficients ${ }^{25}$, we find that only the cross-interaction between age and hours is significantly different between householders and their partner in male same-sex households. The interaction is significant only in one direction, relatively young cohabiting partners can reduce their labor supply when matching with older householders. The difference is non-significant for female same-sex households. We already stated that we were not very confident in the label "householder" to define a particular role in the couple. As additional robustness checks, we assign a particular role to each partner in same-sex couples according to another characteristic. We test if there is a particular role assigned to 1) the older partner, 2) the higher earner (total income) partner. Each partner belongs to a certain population depending to his/her status in the couple, then we estimate a bipartite matching model of the same-sex marriage market on these two populations. Results

\footnotetext{
${ }^{25}$ We provide test results in the online appendix.
} 
are presented on the online appendix. Again, they are not much different from the unipartite case. We now detail some exceptions. When separate populations are defined according to the relative age, we now find a negative interaction between age of the older partner and education and hours worked of the younger partner among gay couples. When separate populations are defined according to the relative total income, symmetry is respected for all coefficients for male same-sex couples but not for female same-sex couples. Specialized roles may appear among lesbian couples as they are more likely to have children. There are asymmetries in the interaction between hours and education, hours and wage and education and wage. The coefficient of interaction between education and wage is always high and positive but it is much higher between the education of the higher earner and wage of the lower earner than the other way around.

5.4. Matching on unobservables. Thanks to assumption 4, we can evaluate the parameter $\sigma$ for each market. As anticipated in section 2, this parameter has a simple interpretation: the higher $\sigma$, the more matching appears as random to the econometrician, or, in other words, the higher the entropy. Since our observable characteristics are meant to capture the main socio-economic traits, we expect that a higher $\sigma$ implies that matching is less "deterministic": indeed, for higher $\sigma$, the socio-economic background of an individual matters relatively less, whereas other unobservable traits (e.g. personality or physical appearance) may matter relatively more.

We find that entropy is higher on same-sex marriage markets (1.26 for gay men and 1.23 for lesbians), whereas it is lower on different-sex marriage markets (1.04 for unmarried couples and 1.00 for married). Hence, if we interpret entropy as due to the relevance of unobservables, it seems that, among same-sex couples, socio-economic background matters less relatively to unobservable traits.

While we privilege an interpretation of $\sigma$ that is consistent with Becker's frictionless matching model, it is important to recall that differences in the search process are also captured by $\sigma$. All else held constant, stronger search frictions should result in higher entropy (Shimer \& Smith, 2000). However, we are not able to disentangle the effects of search frictions from the relevance of unobservables. This may be problematic when comparing the same- and different-sex marriage markets because gays constitute a relatively small part of the population. If the frequency of 
meetings is increasing in the size of the pool of potential partners, as suggested by the search-andmatching literature ${ }^{26}$, then we should expect search frictions to be stronger for the gay population. In order to address this issue, we estimate the affinity matrix for a subsample of couples living in the metropolitan areas of Los Angeles and San Francisco. We expect search frictions to be small in densely populated urban areas, and meeting opportunities to be comparable for homosexuals and heterosexuals. While the point-estimates of $\sigma$ are almost unchanged for different-sex couples (1.03 for unmarried, 1.00 for married), we observe an increase for both gay men (1.35) and lesbians $(1.32)^{27}$. Since the estimates of $\sigma$ for same-sex couples are persistently higher even in areas where search frictions are expected to be lower, we conjecture that the difference in entropy can, at least in part, be explained by unobservable traits.

5.5. Saliency analysis. A way to bring further insights on the main drivers of preferences of individuals over different characteristics is to decompose the affinity matrix in orthogonal dimensions. As detailed in section 3.3, we conduct the decomposition analysis on all variables, with a specific treatment for race, a categorical variable. Under the parametrization (3.5), we estimate the affinity matrix driving the interactions of the non-race characteristics, and the coefficient $\lambda_{R}$ which measures the homogamy on race. We obtain

$$
\Phi(x, y)=\sum_{p=1}^{K} \lambda_{p} \tilde{x}^{p} \tilde{y}^{p}+\lambda_{R} 1\left\{x^{R}=y^{R}\right\}
$$

where $\tilde{x}^{p}$ is the $p$-th index associated to the individual with characteristics $x$ obtained by the decomposition, and $x^{R}$ is the race characteristics. Taking expectations with respect to the sample distribution

$$
\mathbb{E}_{\hat{\pi}}[\Phi(X, Y)]=\sum_{p=1}^{K} \lambda_{p} \mathbb{E}_{\hat{\pi}}\left[\tilde{X}^{p} \tilde{Y}^{p}\right]+\lambda_{R} \mathbb{E}_{\hat{\pi}}\left[1\left\{X^{R}=Y^{R}\right\}\right],
$$

this allows us to decompose the average surplus $\mathbb{E}_{\hat{\pi}}[\Phi(X, Y)]$ into the sum of the surplus created by the interaction between characteristics $p$, namely $\lambda_{p} \mathbb{E}_{\hat{\pi}}\left[\tilde{X}^{p} \tilde{Y}^{p}\right]$, plus the surplus created by

\footnotetext{
${ }^{26}$ In the search-and-matching literature, the meeting rate is usually modeled as a constant return to scale function of vacancies of both sides of the market, usually a Cobb-Douglas function. This assumption seems to be supported empirically on the labor market (Petrongolo \& Pissarides, 2001). On the marriage market, Goussé et al., 2017 also use a Cobb-Douglas matching function.

${ }^{27}$ Complete tables of results obtained with the subsample of couples residing in urban areas are available in the online appendix. Urban areas are defined as the Metropolitan Statistical Areas of Los Angeles and San Francisco.
} 
homogamy on the racial characteristics $\lambda_{R} \mathbb{E}_{\hat{\pi}}\left[1\left\{X^{R}=Y^{R}\right\}\right]$. We present such a decomposition in the appendix in table 6 . First, we show that the share of the average surplus created by homogamy on the racial characteristics reaches more than $47 \%$ for different-sex couples, $42 \%$ for lesbian couples and only $33 \%$ for gays. Then, the rest of the average surplus can mainly be explained in two orthogonal dimensions which measure relative attractiveness. These indices load on different characteristics of individuals. For the different-sex and the lesbian marriage market, the first index is almost only composed of age. It explains by itself around $36 \%$ of the surplus for married differentsex couples, $33 \%$ for unmarried different-sex couples and $29 \%$ of the surplus for female same-sex couples. Then the second index mostly relies on education for these markets, and explains around $27 \%$ of the sorting for female same-sex couples, $20 \%$ for unmarried different-sex couples and $16 \%$ for different-sex married couples. For male same-sex couples, the first index of sorting relies on education (35\%) then comes ethnicity, then age (30\%). When we consider different-sex couples, the indices of mutual attractiveness could differ between genders. For married heterosexuals, the education/wage index (the second index) loads positively twice as much on wages for men than for women, whereas there is a penalty on working hours for women that does not appear for men.

\section{Discussion And Perspectives}

The contributions of the present paper are twofold. From a methodological point of view, this paper is the first to propose a tractable empirical equilibrium framework for the analysis of same-sex marriage. Our methodology could be applied to many other markets (e.g. roommates, teammates, co-workers). In addition, we apply the model in order to provide an empirical analysis of sorting patterns in the same-sex marriage market in California. We conduct a cross-market comparison: we analyze the heterogeneity in preferences between same-sex and different-sex couples. First, we find that, as concerns age and ethnicity, the different-sex marriage market is characterized by a stronger "preference for homogamy" than the same-sex marriage market. Meanwhile, results are more nuanced when it comes to education: while lesbians show stronger assortativeness on education, there is no significant difference in that dimension between gay male and married different-sex couples. Second, we discuss the differences in complementarity and substitutability in the marriage surplus function as defined in Becker's theory of the family. Our findings suggest that labor market traits are complementary only for same-sex and unmarried cohabiting different-sex couples. The 
presence of children seems to be a central driver of these contrasted findings. These results indicate that the traditional concept of marriage gain based on specialization within the couple is still relevant today, although it applies mainly to couples with children.

Families and household arrangements are evolving quickly and we need to understand the underlying forces of these changes. The need for effective analytical frameworks to study and describe new forms of families has recently emerged in the economic literature, mainly as concerns samesex couples (D. A. Black et al., 2007; Oreffice, 2011) and cohabiting partners (Gemici \& Laufer, 2011; Stevenson \& Wolfers, 2007). Let us briefly discuss both. In this paper, we found structural differences between three separate subpopulations divided according to sexual preferences. However, can we state with certainty that these markets are mutually exclusive? In fact, individuals may endogenously choose into which market they are willing to match. The appendix explores a theoretical framework to move beyond the exogenous selection hypothesis. While the lack of individual-level data on sexual orientation does not allow at this stage to go beyond a theoretical model, we trust that, with the consolidation of the same-sex marriage and the availability of more and more accurate data, it will soon be possible to expand our understanding on these questions. Second, cohabitation is another developing phenomenon (Gemici \& Laufer, 2011; Schwartz \& Graf, 2009; Verbakel \& Kalmijn, 2014) and is associated with a lower degree of specialization and a lower degree of positive assortative mating. A promising area of research would be to understand the preferences for marriage or cohabitation jointly with sorting preferences. Mourifié and Siow, 2014 set a first model in that direction for different-sex couples, which could be adapted to same-sex couples using the techniques put forward in the present paper; see also the empirical analysis of (Verbakel \& Kalmijn, 2014), and Aldén et al., 2015 for the marital and fertility decisions of same-sex households.

Another topic of interest is the effect of new forms of families on the traditional ones over time. Opponents of same-sex marriage have voiced the fear that it will cause the marriage institution to lose its value and favor alternative forms of families, typically more flexible/less stable, such as cohabitation. For now, researchers have found no effect of same-sex marriage on the number of different-sex marriages or on the number of divorces (Trandafir, 2014, 2015). However, we wonder whether the legal recognition of same-sex marriage could someway impact the preferences observed on the different markets. What changes should we expect in the behavior of heterosexuals? And 
could it be that same-sex couples become more homogamous as same-sex marriage is institutionalized?

Finally, in Becker's theory, a rationale for marriage is the home production complementarities between men and women skills. However, the traditional gains from marriage have diminished for two main reasons. First, the progress in home technology has decreased the value of domestic production; second, as women took control over their fertility and have become more and more educated, their opportunity cost of staying at home has increased (Greenwood et al., 2016; Stevenson \& Wolfers, 2007). Despite the decrease in the gains to traditional marriage, the institution of marriage has not disappeared. On the contrary, there has been a high demand for same-sex legal marriage in many developed countries. (Stevenson \& Wolfers, 2007) argue that individuals now look for a mate with whom they "share passions" and the new rationale for marriage is now "consumption complementarities" instead of "production complementarities". It is also possible that the act of marriage itself is still considered as intrinsically valuable for cultural and social reasons. In any case, this evolution may lead to even higher correlation of traits. Time will tell how these changes will impact macroeconomic outcomes, life quality and social distance among individuals.

b Economics Department, Sciences Po, Paris.

Address: Sciences Po, Department of Economics, 27 rue Saint-Guillaume, 75007 Paris, France. Email: edoardo.ciscato@sciencespo.fr.

† New York University, Department of Economics (FAS) and Department of Mathematics (CIMS), and

Toulouse School of Economics, Fondation Jean-Jacques Laffont.

Address: NYU Economics, 19 W 4th Street, New York, NY 10012, USA. Email: ag133@nyu.edu.

$\S$ Economics Department, Laval University.

Address: Université Laval, Département d'Economie, Québec, (QC) G1V 0A6, Canada. Email: marion.gousse@ecn.ulaval.ca. 


\section{REFERENCES}

Aldén, L., Edlund, L., Hammarstedt, M., \& Mueller-Smith, M. (2015). Effect of registered partnership on labor earnings and fertility for same-sex couples: Evidence from swedish register data. Demography, 52(4), 1243-1268.

Allen, D. W., \& Lu, S. E. (2017). Matching, marriage, and children: Differences across sexual orientations. Review of Economics of the Household, 15(2), 527-547.

Andersson, G., Noack, T., Seierstad, A., \& Weedon-Fekjær, H. (2006). The demographics of samesex marriages in norway and sweden. Demography, 43(1), 79-98.

Antecol, H., \& Steinberger, M. D. (2013). Labor supply differences between married heterosexual women and partnered lesbians: A semi-parametric decomposition approach. Economic Inquiry, 51(1), 783-805.

Becker, G. (1973). A theory of marriage: Part I. Journal of Political Economy, 81(4).

Becker, G. (1991). A treatise on the family. Harvard University Press.

Black, D., Gates, G., Sanders, S., \& Taylor, L. (2002). Why do gay men live in san francisco? Journal of Urban Economics, 51(1), 54-76.

Black, D. A., Sanders, S. G., \& Taylor, L. J. (2007). The economics of lesbian and gay families. The Journal of Economic Perspectives, 21(2), 53-70.

Blumstein, P., Schwartz, P. et al. (1983). American couples: Money, work, sex. Morrow New York.

Brien, M. J., Lillard, L. A., \& Stern, S. (2006). Cohabitation, marriage, and divorce in a model of match quality. International Economic Review, 47(2), 451-494.

Candelon, B., \& Dupuy, A. (2015). Hierarchical organization and performance inequality: Evidence from professional cycling. International Economic Review, 56(4), 1207-1236.

Chiappori, P.-A., Oreffice, S., \& Quintana-Domeque, C. (2012). Fatter attraction: Anthropometric and socioeconomic matching on the marriage market. Journal of Political Economy, 120(4), 659-695.

Chiappori, P. A., Galichon, A., \& Salanié, B. (forthcoming). On human capital and team stability. Journal of Human Capital.

Chiappori, P.-A., Salanié, B., \& Weiss, Y. (2017). Partner choice, investment in children, and the marital college premium. American Economic Review, 107(8), 2109-67. 
Choo, E., \& Siow, A. (2006). Who marries whom and why. Journal of Political Economy, 114, $175-201$.

Dagsvik, J. K. (1994). Discrete and continuous choice, max-stable processes, and independence from irrelevant attributes. Econometrica: Journal of the Econometric Society, 1179-1205.

Dagsvik, J. K. (2000). Aggregation in matching markets. International Economic Review, 41(1), $27-58$.

Diamond, L. M. (2008a). Female bisexuality from adolescence to adulthood: Results from a 10-year longitudinal study. Developmental psychology, 44(1), 5.

Diamond, L. M. (2008b). Sexual fluidity. Harvard University Press.

Dillon, F. R., Worthington, R. L., \& Moradi, B. (2011). Sexual identity as a universal process. In S. J. Schwartz, K. Luyckx, \& V. L. Vignoles (Eds.), Handbook of identity theory and research (pp. 649-670). Springer.

Dupuy, A., \& Galichon, A. (2014). Personality traits and the marriage market. Journal of Political Economy, 122(6), 1271-1319.

Eika, L., Mogstad, M., \& Zafar, B. (2014). Educational assortative mating and household income inequality (tech. rep.). JSTOR.

Eskridge Jr, W. N. (1993). A history of same-sex marriage. Virginia Law Review, 1419-1513.

Fox, J. T. (2010). Identification in matching games. Quantitative Economics, 1(2), 203-254.

Fox, J. T. (2018). Estimating matching games with transfers. Quantitative Economics, 9(1), 1-38.

Galichon, A., \& Salanié, B. (2014). Cupid's invisible hand: Social surplus and identification in matching models (tech. rep.). SSRN.

Gates, G. J. (2010). Same-sex couples in us census bureau data: Who gets counted and why (tech. rep.). the Williams Institute.

Gemici, A., \& Laufer, S. (2011). Marriage and cohabitation. New York University, mimeo.

Goldin, C., Katz, L. F., \& Kuziemko, I. (2006). The homecoming of american college women: The reversal of the college gender gap. The Journal of Economic Perspectives, 133-156.

Goussé, M., Jacquemet, N., \& Robin, J.-M. (2017). Marriage, labor supply, and home production. Econometrica, 85(6), 1873-1919. 
Greenwood, J., Guner, N., Kocharkov, G., \& Santos, C. (2016). Technology and the changing family: A unified model of marriage, divorce, educational attainment, and married female labor-force participation. American Economic Journal: Macroeconomics, 8(1), 1-41.

Harry, J. (1984). Gay couples. Praeger Publishers.

Hayes, A. F. (1995). Age preferences for same-and opposite-sex partners. The Journal of social psychology, 135(2), 125-133.

Heckman, J. (2007). Notes on koopmans and beckmann's "assignment problems and the location".

Hines, M. (2011). Gender development and the human brain. Annual review of neuroscience, 34 , 69-88.

Hitsch, G. J., Hortaçsu, A., \& Ariely, D. (2010). Matching and sorting in online dating. American Economic Review, 100(1), 130-63.

Jannini, E. A., Blanchard, R., Camperio-Ciani, A., \& Bancroft, J. (2010). Male homosexuality: Nature or culture? The Journal of Sexual Medicine, 7(10), 3245-3253.

Jepsen, C., \& Jepsen, L. K. (2015). Labor-market specialization within same-sex and difference-sex couples. Industrial Relations: A Journal of Economy and Society, 54(1), 109-130.

Jepsen, L. K., \& Jepsen, C. A. (2002). An empirical analysis of the matching patterns of same-sex and opposite-sex couples. Demography, 39(3), 435-453.

Kalmijn, M. (1998). Intermarriage and homogamy: Causes, patterns, trends. Annual Review of Sociology, 24(1), 395-421.

Kenrick, D. T., \& Keefe, R. C. (1992). Age preferences in mates reflect sex differences in human reproductive strategies. Behavioral and Brain Sciences, 15(01), 75-91.

Kurdek, L. A., \& Schmitt, J. P. (1987). Partner homogamy in married, heterosexual cohabiting, gay, and lesbian couples. Journal of Sex Research, 23(2), 212-232.

Low, C. (2013). Pricing the biological clock: Reproductive capital on the us marriage market (tech. rep.). Mimeo.

Meier, A., Hull, K. E., \& Ortyl, T. A. (2009). Young adult relationship values at the intersection of gender and sexuality. Journal of Marriage and Family, 71(3), 510-525.

Menzel, K. (2015). Large matching markets as two-sided demand systems. Econometrica, 83, 306337. 
Mourifié, I. Y., \& Siow, A. (2014). Cohabitation vs marriage: Marriage matching with peer effects (tech. rep.). University of Toronto.

Oreffice, S. (2011). Sexual orientation and household decision making.: Same-sex couples' balance of power and labor supply choices. Labour Economics, 18(2), 145-158.

Peski, M. (2017). Large roommate problem with non-transferable random utility. Journal of Economic Theory, 168, 432-471.

Petrongolo, B., \& Pissarides, C. A. (2001). Looking into the black box: A survey of the matching function. Journal of Economic literature, 39(2), 390-431.

Rodriguez, C. E. (2000). Changing race: Latinos, the census, and the history of ethnicity in the united states. NYU Press.

Rosenfeld, M. J., \& Kim, B.-S. (2005). The independence of young adults and the rise of interracial and same-sex unions. American Sociological Review, 70(4), 541-562.

Schwartz, C. R., \& Graf, N. L. (2009). Assortative matching among same-sex and different-sex couples in the united states, 1990-2000. Demographic research, 21, 843.

Sell, R. L. (1997). Defining and measuring sexual orientation: A review. Archives of sexual behavior, 26(6), 643-658.

Shimer, R., \& Smith, L. (2000). Assortative matching and search. Econometrica, 68(2), 343-369.

Stevenson, B. (2008). The evolution of the american family: An economic interpretation. American Journal of Family Law, 22(3), 141-147.

Stevenson, B., \& Wolfers, J. (2007). Marriage and divorce: Changes and their driving forces. The Journal of Economic Perspectives, 27-52.

Sullivan, A. (2009). Same-sex marriage: Pro and con. Random House LLC.

Trandafir, M. (2014). The effect of same-sex marriage laws on different-sex marriage: Evidence from the netherlands. Demography, 51(1), 317-340.

Trandafir, M. (2015). Legal recognition of same-sex couples and family formation. Demography, 52(1), 113-151.

Verbakel, E., \& Kalmijn, M. (2014). Assortative mating among dutch married and cohabiting same-sex and different-sex couples. Journal of Marriage and Family, 76(1), 1-12. 
Virgile, M. (2011). Measurement error in the relationship status of same-sex couples in the 2009 american community survey (tech. rep.). ACS11-RER-10, US Government Printing Office, Washington, DC.

Weiss, Y., Yi, J., \& Zhang, J. (2013). Hypergamy, cross-boundary marriages, and family behavior (tech. rep.). IZA Discussion Paper.

\section{Appendix A. Pooled matching market with Sexual orientation}

In this appendix, we consider a model with endogenous selection of the partner's gender. In this model, gender and sexual orientation are observable characteristics among others. This model therefore assumes that all the individuals are pooled into one market, and that the partner's gender is endogenously chosen and determined based on market characteristics, and in particular, it is subject to trade-offs with other variables. While we include this model for completeness, we regard it as a theoretical construction in the absence of matched data including a measure of sexual of orientation, and we do not present it in the main paper. The model that we use in the main body of the paper operates under the limiting assumption that sexual orientation fully determines the partner's gender (assumption 3), which is why we assume in the paper that there are three completely segmented markets: lesbian, gay, and heterosexual.

In reality, segmentation may not be perfect, and some people might face trade-offs between matching with someone of their preferred gender rather than an attractive person of the less preferred gender. In addition, some people might be equally attracted by both genders (i.e., bisexual). Assumption 3 implies that we disregard these trade-offs.

Consider a model where individuals are represented by: (i) their economic characteristics $x_{e}$; (ii) their gender $x_{g}$, which is a dummy variable equal to 0 if male, 1 if female (this could be extended to a continuous gender spectrum in which case $x_{g}$ may vary continuously between 0 and 1 ); and (iii) a measure of sexual orientation $x_{o}$ which is set so that $x_{o}=1$ if the individual is maximally interested 
in women, and $x_{o}=0$ if maximally interested in $\operatorname{men}^{28}$. In this case, letting $x=\left(x_{e}, x_{g}, x_{o}\right)$, the affinity model will result in an affinity matrix written blockwise as

$$
A=\left(\begin{array}{ccc}
A^{e e} & A^{e g} & A^{e o} \\
* & A^{g g} & A^{g o} \\
* & * & A^{o o}
\end{array}\right)
$$

where the stars denote terms that are omitted due to the symmetry of $A$. Several components of $A$ are especially interesting:

- $A^{e e}$ is the classical affinity matrix between the socio-economic and demographic characteristics of the partners, and measures the pairwise assortativeness on education, age, income, race etc. Positive entries of $A^{e e}$ denote complementarity between these characteristics.

- $A^{g o}$ denotes the affinity between sexual orientation and gender, which is expected to be positive, by the very definition of $x_{o}$.

- $A^{g g}$ denotes the utility penalization of same-sex couples with respect to different-sex ones, which we expect to be negative, in particular due to the relatively higher cost of bearing children for these households, and perhaps also due to social pressure in traditional societies.

In this model, there is a trade-off in surplus between a term that reflects homogamy on socioeconomic characteristics (whose strength is determined by $A^{e e}$ ), a term that reflects sexual orientation (whose strength is determined by $A^{g o}$ ), and a term that reflects in particular the higher cost of bearing children (whose strength is determined by $A^{g g}$ ).

Note that, in the limit where the affinity term $A^{g o}$ between gender and sexual preference is very strong $\left(A^{g o} \rightarrow+\infty\right)$, we get a full segmentation of the markets, where the partner's choice is fully determined by sexual orientation. In this case, we get a sequential choice model where the agents choose in a first stage which market (same-sex or different-sex) to enter, and then choose the remaining partner's characteristics. Because we do not observe sexual orientation, we decided

\footnotetext{
${ }^{28}$ Sexual orientation can be measured for instance by the means of the Kinsey scale (see Sell, 1997, for a review), which is a number between 0 (exclusively heterosexual) and 6 (exclusively homosexual). If $k$ is the value of the Kinsey scale, $x_{o}$ will be set to $k / 6$ if the individual is a woman, and to $1-k / 6$ if the individual is a man, which is summarized in the formula $x_{o}:=x_{g}(k / 6)+\left(1-x_{g}\right)(1-k / 6)$.
} 
to adopt this limiting case as our framework, thus making the assumption that $A^{g o}$ is very large with respect to the other terms. 
Appendix B. Descriptive statistics

\begin{tabular}{lcccccc}
\multicolumn{1}{c}{ Type of couples } & Age & Education & Wage & Hours & Sample size & Share \\
\hline Married Heterosexuals & & & & & & $87.39 \%$ \\
Men & 40.22 & 12.33 & 31.34 & 43.60 & 124,772 & \\
Women & 38.37 & 12.47 & 22.84 & 36.16 & 124,772 & \\
Unmarried Heterosexuals & & & & & & $11.33 \%$ \\
Men & 36.31 & 11.17 & 19.79 & 41.33 & 16,174 & \\
Women & 34.84 & 11.55 & 18.45 & 38.30 & 16,174 & \\
Homosexuals & & & & & & \\
Men & 40.00 & 13.93 & 35.19 & 42.71 & 2,034 & $0.71 \%$ \\
Women & 39.35 & 13.78 & 28.44 & 40.74 & 1,620 & $0.57 \%$ \\
\hline
\end{tabular}

TABLE 1. Sample means (25-50 year old)

\begin{tabular}{l|ccc|c} 
Ethnic & Heterosexual & Gay & Lesbian & All \\
\hline White & 42.7 & 67.3 & 63.5 & 43.0 \\
Black & 2.9 & 2.5 & 5.2 & 2.9 \\
Others & 0.6 & 0.8 & 1.2 & 0.6 \\
Asian & 16.7 & 8.8 & 5.8 & 16.6 \\
Hispanic & 37.1 & 20.7 & 24.3 & 36.9 \\
\hline Total & 100.0 & 100.0 & 100.0 & 100.0 \\
\hline
\end{tabular}

TABLE 2. Distribution of race by sexual orientation (25-50 year old)

\begin{tabular}{lcccc}
\multicolumn{1}{c}{ Type of couples } & Age & Education & Wage & Hours \\
\hline Heterosexual married couples & 0.76 & 0.71 & 0.16 & -0.12 \\
Heterosexual unmarried couples & 0.68 & 0.64 & 0.30 & 0.11 \\
Gay couples & 0.56 & 0.56 & 0.15 & 0.03 \\
Lesbian couples & 0.66 & 0.65 & 0.20 & 0.08 \\
\hline
\end{tabular}

TABle 3. Couples' Pearson correlation coefficients 


\begin{tabular}{l|ccccc} 
& White & Black & Others & Asian & Hispanic \\
\hline White & 1.12 & 0.79 & 0.46 & 0.94 & 0.67 \\
Black & & 12.31 & 0.00 & 0,44 & 0.57 \\
Others & & & 40.00 & 2,14 & 1.21 \\
Asian & & & & 3.08 & 0.33 \\
Hispanic & & & & & 2.39 \\
\hline
\end{tabular}

\begin{tabular}{l|ccccc} 
& White & Black & Others & Asian & Hispanic \\
\hline White & 1.28 & 0.39 & 0.74 & 0.70 & 0.47 \\
Black & & 10.67 & 1.00 & 0.82 & 0.53 \\
Others & & & 20.00 & 0.91 & 0.87 \\
Asian & & & & 8.00 & 0.13 \\
Hispanic & & & & & 2.69 \\
\hline
\end{tabular}

(A) Gays

(в) Lesbians

\begin{tabular}{l|ccccc} 
& \multicolumn{5}{|c}{ Women } \\
Men & White & Black & Others & Asian & Hispanic \\
\hline White & 1.96 & 0.32 & 0.87 & 0.37 & 0.28 \\
Black & 0.49 & 24.02 & 1.38 & 0.34 & 0.36 \\
Others & 0.84 & 0.62 & 60.91 & 0.40 & 0.46 \\
Asian & 0.15 & 0.08 & 0.27 & 5.08 & 0.07 \\
Hispanic & 0.26 & 0.16 & 0.44 & 0.09 & 2.32 \\
\hline
\end{tabular}

(c) Heterosexuals

TABLE 4. Homogamy rates (25-50 year old). The homogamy rate is the ratio between the observed number of couples of a certain type and the counterfactual number which should be observed if individuals formed couples randomly. 


\section{Preamble to appendices C, D and E}

In the next three appendices, we present our estimation results. In appendix $\mathrm{C}$, we present our estimates for the main sample. Table 5 presents our estimates of the affinity matrix of each market (table $5 \mathrm{a}$ for the male same-sex marriage market, table 5b for the female same-sex marriage market, table $5 \mathrm{c}$ for the married different-sex marriage market and table $5 \mathrm{~d}$ for the unmarried different-sex market). Table 6 presents the results of our saliency analysis, i.e., the decomposition of the affinity matrices in orthogonal dimensions.

In appendix D, table 7 presents our estimates of the affinity matrix when we perform a bipartite estimation of the same-sex marriage market without requiring the affinity matrix to be symmetric. In this case, we define two separate subpopulations to run a bipartite estimation. On one side of the market, we group all those gay individuals that are registered as "householders", whereas on the other we group their "cohabiting partners". Table 7a displays our estimates for the male same-sex marriage market whereas $7 \mathrm{~b}$ table presents our estimates for the female same-sex marriagemarket.

Finally, in appendix E, table 8 presents our estimation results on additional selected samples: 1) childless couples, 2) bi-earner couples, 3) couples living in the metropolitan area of Los Angeles or San Francisco, 4) young couples (25-35 year old). For different-sex married couples, table 8c also shows our results for couples with one child only, for couples with three children and more, and for recently married couples with no children. In this table, we do not show all the coefficients of the affinity matrix but only the diagonal coefficients. Each sub-table presents the results for a particular market and each row displays the estimates for a particular selected sub-sample of this market. 
REFERENCES

Appendix C. Main estimation Results

\begin{tabular}{l|ccccc} 
& Age & Educ. & Wage & Hours & Race \\
\hline Age & $\mathbf{0 . 6 2}$ & -0.06 & -0.02 & $\mathbf{- 0 . 1 3}$ & \\
& $(0.04)$ & $(0.06)$ & $(0.03)$ & $(0.04)$ & \\
Education & & $\mathbf{0 . 8 4}$ & $\mathbf{0 . 1 3}$ & -0.07 & \\
& & $(0.09)$ & $(0.06)$ & $(0.06)$ & \\
Wage & & & $\mathbf{0 . 0 5}$ & $\mathbf{- 0 . 0 7}$ & \\
& & & $(0.02)$ & $(0.03)$ & \\
Hours & & & & $\mathbf{0 . 1 2}$ & \\
& & & & $(0.04)$ & \\
Race & & & & & $\mathbf{0 . 6 2}$ \\
& & & & & $(0.06)$ \\
\hline $\boldsymbol{\sigma}$ & & & & &
\end{tabular}

(A) Gays (1,017 couples)

\begin{tabular}{l|ccccc} 
& \multicolumn{5}{|c}{ Women } \\
Men & Age & Educ. & Wage & Hours & Race \\
\hline Age & $\mathbf{2 . 1 7}$ & $\mathbf{- 0 . 2 0}$ & -0.01 & -0.03 & \\
& $(0.05)$ & $(0.03)$ & $(0.02)$ & $(0.03)$ & \\
Education & -0.04 & $\mathbf{0 . 8 2}$ & $\mathbf{0 . 1 9}$ & -0.04 & \\
& $(0.03)$ & $(0.03)$ & $(0.03)$ & $(0.03)$ & \\
Wage & $\mathbf{0 . 0 9}$ & $\mathbf{0 . 2 7}$ & $\mathbf{0 . 0 1}$ & $\mathbf{- 0 . 1 3}$ & \\
& $(0.03)$ & $(0.04)$ & $(0.00)$ & $(0.02)$ & \\
Hours & $\mathbf{0 . 0 6}$ & $\mathbf{0 . 0 9}$ & $\mathbf{- 0 . 0 9}$ & $\mathbf{- 0 . 0 4}$ & \\
& $(0.02)$ & $(0.02)$ & $(0.01)$ & $(0.02)$ & \\
Race & & & & & $\mathbf{2 . 4 9}$ \\
& \multicolumn{5}{|c}{1.00} \\
\hline$\sigma$ & & & & & $(0.04)$ \\
\hline
\end{tabular}

(C) Married heterosexuals (6,228 couples)

\begin{tabular}{l|ccccc} 
& Age & Educ. & Wage & Hours & Race \\
\hline Age & $\mathbf{0 . 7 9}$ & 0.04 & 0.05 & $\mathbf{- 0 . 1 0}$ & \\
& $(0.05)$ & $(0.07)$ & $(0.06)$ & $(0.05)$ & \\
Education & & $\mathbf{1 . 1 9}$ & $\mathbf{0 . 2 0}$ & -0.01 & \\
& & $(0.12)$ & $(0.10)$ & $(0.07)$ & \\
Wage & & & 0.06 & $\mathbf{- 0 . 1 9}$ & \\
& & & $(0.04)$ & $(0.05)$ & \\
Hours & & & & $\mathbf{0 . 2 0}$ & \\
& & & & $(0.05)$ & \\
Race & & & & & $\mathbf{1 . 2 6}$ \\
& & \multicolumn{5}{c}{1.23} \\
\hline$\sigma$ & & & & & \\
\hline
\end{tabular}

(B) Lesbians (810 couples)

\begin{tabular}{|c|c|c|c|c|c|}
\hline \multirow[b]{2}{*}{ Men } & \multicolumn{5}{|c|}{ Women } \\
\hline & Age & Educ. & Wage & Hours & Race \\
\hline \multirow[t]{2}{*}{ Age } & 1.14 & -0.06 & 0.00 & -0.06 & \\
\hline & $(0.03)$ & (0.02) & (0.02) & (0.02) & \\
\hline \multirow[t]{2}{*}{ Education } & -0.07 & 0.66 & 0.37 & 0.05 & \\
\hline & (0.02) & (0.02) & $(0.04)$ & (0.02) & \\
\hline \multirow[t]{2}{*}{ Wage } & 0.01 & 0.21 & 0.05 & 0.06 & \\
\hline & $(0.04)$ & $(0.05)$ & $(0.01)$ & $(0.03)$ & \\
\hline \multirow[t]{2}{*}{ Hours } & -0.05 & -0.02 & 0.05 & 0.09 & \\
\hline & (0.02) & (0.02) & (0.02) & (0.02) & \\
\hline \multirow[t]{2}{*}{ Race } & & & & & 1.98 \\
\hline & & & & & $(0.04)$ \\
\hline$\sigma$ & & & 1.04 & & \\
\hline
\end{tabular}

(D) Unmarried heterosexuals (5,645 couples)

TAble 5. Affinity matrix: The tables display estimates of the affinity matrix $A$ obtained with a sample of couples where both partners are aged between 25 and 50 . If the entry $A_{i j}$ is positive and significant, then trait $i$ and $j$ are found to be complements in the marital surplus function. On the contrary, if $A_{i j}$ is negative and significant, $i$ and $j$ are substitutes. Standard errors are in parentheses. Boldfaced estimates are significant at the 5 percent level. 


\begin{tabular}{l|cc|c} 
& I1 & I2 & Ethnicity \\
\hline Age & 0.11 & 0.97 & \\
Education & 0.94 & -0.15 & \\
Wage & 0.27 & -0.04 & \\
Hours & -0.19 & -0.19 & \\
\hline Share of systematic surplus & $35 \%$ & $30 \%$ & $33 \%$ \\
\hline
\end{tabular}

(A) Gays (1,017 couples)

\begin{tabular}{l|cc|c} 
& I1 & I2 & Ethnicity \\
\hline Age & 0.98 & -0.17 & \\
Education & 0.15 & 0.97 & \\
Wage & 0.09 & 0.19 & \\
Hours & -0.13 & -0.03 & \\
\hline Share of systematic surplus & $29 \%$ & $27 \%$ & $42 \%$ \\
\hline
\end{tabular}

(в) Lesbians (810 couples)

\begin{tabular}{l|cc|cc|c} 
& \multicolumn{2}{|c|}{ I1 } & \multicolumn{2}{|c|}{ I2 } & Ethnicity \\
& Men & Women & Men & Women & \\
\hline Age & 1.05 & 1.02 & 0.04 & 0.11 & \\
Education & -0.06 & -0.11 & 0.86 & 0.97 & \\
Wage & 0.03 & -0.01 & 0.31 & 0.18 & \\
Hours & 0.02 & -0.02 & 0.09 & -0.14 & \\
\hline Share of systematic surplus & \multicolumn{2}{|c|}{$36 \%$} & \multicolumn{2}{|c|}{$16 \%$} & $48 \%$ \\
\hline
\end{tabular}

(c) Married heterosexuals (6,228 couples)

\begin{tabular}{l|cc|cc|c} 
& \multicolumn{2}{|c|}{ I1 } & \multicolumn{2}{c|}{ I2 } & Ethnicity \\
& Men & Women & Men & Women & \\
\hline Age & 0.96 & 0.95 & 0.12 & 0.12 & \\
Education & -0.13 & -0.12 & 0.97 & 0.93 & \\
Wage & -0.02 & -0.04 & 0.30 & 0.51 & \\
Hours & -0.04 & -0.05 & -0.01 & 0.08 & \\
\hline Share of systematic surplus & \multicolumn{2}{|c|}{$33 \%$} & \multicolumn{2}{|c|}{$20 \%$} & $47 \%$ \\
\hline
\end{tabular}

(D) Unmarried heterosexuals (5,645 couples)

TABle 6. IndiCES OF ATTRACTIVEnEss: Each column displays the estimates of factor loadings explaining the composition of the $p$-th index of attractiveness $\tilde{x}^{p}$ and the corresponding share of average systematic surplus $\mathbb{E}_{\hat{\pi}}[\Phi(X, Y)]$ explained by such index (see section 5.5). For each market, we present the two indices that explain the largest shares of surplus, as well as the share of surplus explained by ethnicity. Estimates are obtained with a sample of couples where both partners are aged between 25 and 50 . 
Appendix D. Bipartite estimation for same-Sex Couples: head/SPOUSE

\begin{tabular}{l|ccccc}
\multirow{2}{*}{ Head } & \multicolumn{5}{|c}{ Partner } \\
\hline Age & Age & Educ. & Wage & Hours & Race \\
\hline \multirow{4}{*}{ Education } & $\mathbf{0 . 6 0}$ & -0.06 & -0.00 & $\mathbf{- 0 . 1 7}$ & \\
& $(0.04)$ & $(0.05)$ & $(0.03)$ & $(0.04)$ & \\
\multirow{3}{*}{ Wage } & 0.00 & $\mathbf{0 . 8 0}$ & $\mathbf{0 . 1 2}$ & -0.02 & \\
& $(0.06)$ & $(0.08)$ & $(0.05)$ & $(0.06)$ & \\
\multirow{3}{*}{ Hours } & -0.01 & $\mathbf{0 . 1 6}$ & $\mathbf{0 . 0 6}$ & $\mathbf{- 0 . 0 7}$ & \\
& $(0.04)$ & $(0.07)$ & $(0.02)$ & $(0.04)$ & \\
Race & -0.05 & -0.09 & -0.04 & $\mathbf{0 . 1 1}$ & \\
& $(0.04)$ & $(0.05)$ & $(0.03)$ & $(0.04)$ & $(0.03)$ \\
\hline $\boldsymbol{\sigma}$ & & & & & $\mathbf{0 . 6 5}$ \\
& & & & & $(0.06)$ \\
\hline
\end{tabular}

(A) Gays $(1,017$ couples)

\begin{tabular}{l|ccccc} 
& \multicolumn{5}{|c}{ Partner } \\
Head & Age & Educ. & Wage & Hours & Race \\
\hline Age & $\mathbf{0 . 7 4}$ & 0.02 & 0.06 & -0.05 & \\
& $(0.05)$ & $(0.07)$ & $(0.05)$ & $(0.04)$ & \\
Education & 0.05 & $\mathbf{1 . 1 8}$ & $\mathbf{0 . 1 8}$ & 0.05 & \\
& $(0.07)$ & $(0.12)$ & $(0.09)$ & $(0.07)$ & $(0.04)$ \\
Wage & 0.02 & $\mathbf{0 . 1 7}$ & $\mathbf{0 . 0 8}$ & $\mathbf{- 0 . 2 4}$ & \\
& $(0.05)$ & $(0.10)$ & $(0.03)$ & $(0.05)$ & \\
Hours & $\mathbf{- 0 . 1 1}$ & -0.07 & $\mathbf{- 0 . 1 5}$ & $\mathbf{0 . 2 1}$ & \\
& $(0.04)$ & $(0.07)$ & $(0.05)$ & $(0.04)$ & \\
Race & & & & & $\mathbf{1 . 1 8}$ \\
& \multicolumn{5}{|c}{} \\
\hline $\boldsymbol{\sigma}$ & \multicolumn{7}{|c}{1.33} \\
\hline
\end{tabular}

(B) Lesbians (810 couples)

TABle 7. Affinity matrix: The tables display estimates of $A$ in a bipartite market where one side is represented by the population of "heads of household" and the other side by the "head's partners". Contrarily to the matrices $A$ estimated in $5 \mathrm{a}$ and $5 \mathrm{~b}$, now $A$ does not need to be symmetric: symmetry tests can be found in the online appendix. We use a sample of same-sex couples where both partners are aged between 25 and 50. Standard errors are in parentheses. Boldfaced estimates are significant at the 5 percent level. 


\section{Appendix E. Further Robustness CHECKS}

\begin{tabular}{l|ccccc} 
& Age & Educ. & Wage & Hours & Race \\
\hline All & $\mathbf{0 . 6 2}$ & $\mathbf{0 . 8 4}$ & $\mathbf{0 . 0 5}$ & $\mathbf{0 . 1 2}$ & $\mathbf{0 . 6 2}$ \\
& $(0.04)$ & $(0.09)$ & $(0.02)$ & $(0.04)$ & $(0.06)$ \\
\hline Childless & $\mathbf{0 . 5 6}$ & $\mathbf{0 . 6 5}$ & $\mathbf{0 . 0 6}$ & $\mathbf{0 . 1 8}$ & $\mathbf{0 . 4 6}$ \\
& $(0.04)$ & $(0.09)$ & $(0.02)$ & $(0.04)$ & $(0.07)$ \\
Both working & $\mathbf{0 . 6 4}$ & $\mathbf{1 . 2 0}$ & $\mathbf{0 . 0 6}$ & $\mathbf{0 . 2 9}$ & $\mathbf{0 . 5 6}$ \\
& $(0.05)$ & $(0.12)$ & $(0.02)$ & $(0.09)$ & $(0.07)$ \\
Urban & $\mathbf{0 . 6 0}$ & $\mathbf{0 . 9 4}$ & 0.04 & $\mathbf{0 . 1 6}$ & $\mathbf{0 . 4 9}$ \\
& $(0.05)$ & $(0.13)$ & $(0.02)$ & $(0.05)$ & $(0.08)$ \\
25-35 year old & $\mathbf{2 . 4 8}$ & $\mathbf{1 . 0 7}$ & $\mathbf{0 . 3 5}$ & 0.01 & $\mathbf{0 . 8 8}$ \\
& $(0.49)$ & $(0.28)$ & $(0.13)$ & $(0.13)$ & $(0.16)$ \\
\hline
\end{tabular}

(A) Gay couples

\begin{tabular}{l|ccccc} 
& Age & Educ. & Wage & Hours & Race \\
\hline All & $\mathbf{2 . 1 7}$ & $\mathbf{0 . 8 2}$ & $\mathbf{0 . 0 1}$ & -0.04 & $\mathbf{2 . 4 9}$ \\
& $(0.05)$ & $(0.03)$ & $(0.00)$ & $(0.02)$ & $(0.04)$ \\
\hline Childless & $\mathbf{1 . 8 8}$ & $\mathbf{1 . 0 1}$ & $\mathbf{0 . 0 7}$ & $\mathbf{0 . 1 2}$ & $\mathbf{2 . 1 0}$ \\
\multirow{5}{*}{ One child } & $(0.04)$ & $(0.04)$ & $(0.01)$ & $(0.02)$ & $(0.04)$ \\
& $\mathbf{2 . 1 4}$ & $\mathbf{0 . 8 1}$ & $\mathbf{0 . 0 4}$ & 0.02 & $\mathbf{2 . 3 8}$ \\
Three children & $(0.05)$ & $(0.03)$ & $(0.01)$ & $(0.02)$ & $(0.04)$ \\
Newlyweds, childless & $\mathbf{2 . 3 8}$ & $\mathbf{0 . 7 5}$ & $\mathbf{0 . 0 2}$ & -0.02 & $\mathbf{2 . 6 9}$ \\
& $(0.05)$ & $(0.02)$ & $(0.00)$ & $(0.02)$ & $(0.04)$ \\
Both working & $\mathbf{1 . 4 0}$ & $\mathbf{1 . 3 7}$ & $\mathbf{0 . 0 2}$ & $\mathbf{0 . 1 6}$ & $\mathbf{1 . 8 1}$ \\
& $(0.05)$ & $(0.09)$ & $(0.01)$ & $(0.03)$ & $(0.05)$ \\
Urban & $\mathbf{2 . 4 4}$ & $\mathbf{0 . 9 4}$ & $\mathbf{0 . 0 4}$ & $\mathbf{0 . 2 0}$ & $\mathbf{2 . 3 6}$ \\
& $(0.05)$ & $(0.04)$ & $(0.01)$ & $(0.04)$ & $(0.04)$ \\
25-35 year old & $\mathbf{2 . 1 8}$ & $\mathbf{0 . 8 6}$ & $\mathbf{0 . 0 2}$ & $\mathbf{- 0 . 0 4}$ & $\mathbf{2 . 5 9}$ \\
& $(0.05)$ & $(0.03)$ & $(0.00)$ & $(0.02)$ & $(0.04)$ \\
& $\mathbf{6 . 3 3}$ & $\mathbf{1 . 4 2}$ & $\mathbf{0 . 0 7}$ & $\mathbf{0 . 0 6}$ & $\mathbf{3 . 0 9}$ \\
& $(0.17)$ & $(0.05)$ & $(0.02)$ & $(0.03)$ & $(0.05)$ \\
\hline \multirow{5}{*}{} & & & & &
\end{tabular}

(c) Married couples

\begin{tabular}{l|ccccc} 
& Age & Educ. & Wage & Hours & Race \\
\hline All & $\mathbf{0 . 7 9}$ & $\mathbf{1 . 1 9}$ & 0.06 & $\mathbf{0 . 2 0}$ & $\mathbf{1 . 2 6}$ \\
& $(0.05)$ & $(0.12)$ & $(0.04)$ & $(0.05)$ & $(0.07)$ \\
\hline Childless & $\mathbf{0 . 7 6}$ & $\mathbf{0 . 9 1}$ & 0.11 & $\mathbf{0 . 3 4}$ & $\mathbf{1 . 1 3}$ \\
& $(0.06)$ & $(0.15)$ & $(0.06)$ & $(0.06)$ & $(0.09)$ \\
Both working & $\mathbf{0 . 8 5}$ & $\mathbf{1 . 5 7}$ & 0.07 & $\mathbf{0 . 2 0}$ & $\mathbf{1 . 1 5}$ \\
& $(0.06)$ & $(0.16)$ & $(0.04)$ & $(0.09)$ & $(0.08)$ \\
Urban & $\mathbf{0 . 8 7}$ & $\mathbf{1 . 6 2}$ & -0.00 & 0.13 & $\mathbf{1 . 0 8}$ \\
& $(0.08)$ & $(0.21)$ & $(0.04)$ & $(0.07)$ & $(0.10)$ \\
25-35 year old & $\mathbf{1 . 3 4}$ & $\mathbf{1 . 3 8}$ & -0.18 & $\mathbf{0 . 4 3}$ & $\mathbf{1 . 3 3}$ \\
& $(0.34)$ & $(0.27)$ & $(0.31)$ & $(0.10)$ & $(0.15)$ \\
\hline
\end{tabular}

(B) Lesbian couples

\begin{tabular}{l|ccccc} 
& Age & Educ. & Wage & Hours & Race \\
\hline All & $\mathbf{1 . 1 4}$ & $\mathbf{0 . 6 6}$ & $\mathbf{0 . 0 5}$ & $\mathbf{0 . 0 9}$ & $\mathbf{1 . 9 8}$ \\
& $(0.03)$ & $(0.02)$ & $(0.01)$ & $(0.02)$ & $(0.04)$ \\
\hline Childless & $\mathbf{1 . 1 1}$ & $\mathbf{0 . 9 0}$ & $\mathbf{0 . 0 4}$ & $\mathbf{0 . 2 4}$ & $\mathbf{1 . 4 7}$ \\
& $(0.03)$ & $(0.04)$ & $(0.01)$ & $(0.02)$ & $(0.04)$ \\
Both working & $\mathbf{1 . 1 9}$ & $\mathbf{0 . 7 0}$ & $\mathbf{0 . 1 8}$ & $\mathbf{0 . 4 7}$ & $\mathbf{1 . 8 3}$ \\
& $(0.03)$ & $(0.03)$ & $(0.02)$ & $(0.04)$ & $(0.03)$ \\
Urban & $\mathbf{1 . 1 5}$ & $\mathbf{0 . 6 1}$ & $\mathbf{0 . 0 2}$ & $\mathbf{0 . 0 8}$ & $\mathbf{2 . 0 0}$ \\
& $(0.03)$ & $(0.02)$ & $(0.0)$ & $(0.02)$ & $(0.04)$ \\
$25-35$ year old & $\mathbf{3 . 5 8}$ & $\mathbf{1 . 0 8}$ & $\mathbf{0 . 1 5}$ & $\mathbf{0 . 1 9}$ & $\mathbf{2 . 4 5}$ \\
& $(0.11)$ & $(0.04)$ & $(0.03)$ & $(0.03)$ & $(0.04)$ \\
\hline
\end{tabular}

(D) Unmarried couples

TABle 8. Summary tables: Each row displays the estimates of the diagonal coefficients of the affinity matrix $A$ obtained with a given sample. The first row ("All") refers to our benchmark results already presented in table 5 . The other rows refer to alternative subsamples used to conduct our auxiliary estimations. Complete tables with all entries of $A$ are available in the online appendix. Standard errors are in parentheses. Boldfaced estimates are significant at the 5 percent level. 